\title{
A review of structural neuroimaging in schizophrenia: from connectivity to connectomics
}

\author{
Anne L. Wheeler ${ }^{1,2}$ and Aristotle N. Voineskos ${ }^{1,2 *}$ \\ ${ }^{1}$ Kimel Family Translational Imaging Genetics Laboratory, Centre for Addiction and Mental Health, Research Imaging Centre, Toronto, ON, Canada \\ ${ }^{2}$ Department of Psychiatry, University of Toronto, Toronto, ON, Canada
}

\author{
Edited by: \\ Michele Ribolsi, Univesity of Rome \\ Tor Vergata, Italy \\ Reviewed by: \\ Qingbao Yu, The Mind Research \\ Network, USA \\ Peter Kochunov, University of \\ Maryland School of Medicine, USA \\ *Correspondence: \\ Aristotle N. Voineskos, Research \\ Imaging Centre, Centre for \\ Addiction and Mental Health, 250 \\ College St. Toronto, ON M5T 1R8, \\ Canada \\ e-mail: aristotle.voineskos@camh.ca
}

In patients with schizophrenia neuroimaging studies have revealed global differences with some brain regions showing focal abnormalities. Examining neurocircuitry, diffusion-weighted imaging studies have identified altered structural integrity of white matter in frontal and temporal brain regions and tracts such as the cingulum bundles, uncinate fasciculi, internal capsules and corpus callosum associated with the illness. Furthermore, structural co-variance analyses have revealed altered structural relationships among regional morphology in the thalamus, frontal, temporal and parietal cortices in schizophrenia patients. The distributed nature of these abnormalities in schizophrenia suggests that multiple brain circuits are impaired, a neural feature that may be better addressed with network level analyses. However, even with the advent of these newer analyses, a large amount of variability in findings remains, likely partially due to the considerable heterogeneity present in this disorder.

Keywords: magnetic resonance imaging, diffusion tensor imaging, schizophrenia, connectomics, connectivity, white matter

\section{INTRODUCTION}

Schizophrenia affects approximately $1 \%$ of the population and is characterized by disordered thought processes as well as impaired emotional responses. The underlying neural substrates of schizophrenia likely involve alterations of brain circuitry. In vivo neuroimaging approaches have made significant inroads toward the description of these brain abnormalities though variability in results has precluded consensus on precise neural correlates of the illness. The majority of neuroimaging studies examine the brains of chronic patients who have lived with schizophrenia for years. What cannot be known from these results is the timing of brain changes: were they present before the onset of the disease, or did they manifest over the course of the illness? These two hypotheses are not mutually exclusive, but cannot be teased apart in studies that examine brain structure and function in chronic patients. Additionally, the vast majority of patients in these studies are taking antipsychotic medications to treat the symptoms of the illness and the effects of long-term medication exposure on brain structure could confound interpretation of these results. The examination of patients who are early in the course of the illness (first episode) and often have not been treated with medication, as well as groups that are at a high risk for developing the disorder (high-risk and family studies), aim to address these issues. Moreover, understanding brain abnormalities in these groups may make it possible to identify vulnerability early and allow for interventions to help prevent or delay progression to chronic illness.

As distributed structural circuits of cortical and subcortical areas serve normal brain functions, disrupted communication within and between brain regions may be the core pathology of schizophrenia. Two decades ago it was proposed that the symptoms of schizophrenia were due to alterations in cerebral connectivity (Friston and Frith, 1995), a hypothesis that has been gaining traction in recent years with the availability of advanced imaging techniques that can be used to address this theory (Kochunov and Hong, 2014). White matter in the brain consists of the axonal projections to other neurons and brain areas and forms the basis for connectivity in the brain. Structural integrity of white matter can be examined indirectly with diffusion-weighted imaging. Alternatively, computing interregional correlations of regional gray matter morphology (structural co-variance) can assess coupling of brain regions, an index of connectivity (Alexander-Bloch et al., 2013). The application of complex network analysis methods has aided in the description of altered connectivity in the brains of schizophrenia patients. Widespread variability of results exists in structural connectivity studies in all types of schizophrenia patients and high-risk subjects. Several factors likely contribute to these inconsistencies in findings including methodological differences between studies, variability in the clinical presentation of schizophrenia, differences in causal mechanisms underlying schizophrenia and variation in moderator variables across studies.

\section{DIFFUSION WEIGHTED IMAGING STUDIES}

Diffusion tensor imaging (DTI), a diffusion-weighted MRI method, assesses the diffusion of water molecules in order to map microscopic details about white matter fiber structure. It is based on the principle that water moves most easily along axonal bundles because there is the smallest number of obstacles to prevent movement in this direction. Diffusion measurements along 
different axes are fitted to a 3D ellipsoid (tensor) at each voxel. The most commonly assessed metric in DTI studies is fractional anisotropy (FA). FA reflects the magnitude and directionality of water diffusion. Specifically, FA represents the fraction of the tensor that can be assigned to diffusion that is constrained along one axis only, known as anisotropic diffusion. FA values are scaled from 0 (isotropic) to 1 (anisotropic). FA and other DTI metrics are thought to reflect the microstructural properties of white matter tracts, including abnormal coherence of the fiber tracts, fiber density, axonal diameter, and myelination, although the exact microstructural correlates are not clear. Different methods are available to analyze DTI scans. Tractography allows probable trajectories of fiber tracts to be calculated and visualized with an index of fiber integrity averaged over the reconstructed tract, allowing tract-specific measurements. In voxel-based morphometry (VBM) structural images are spatially normalized onto a stereotaxic brain atlas, which allows DTI metrics to be calculated on a voxel by voxel basis. Statistical comparison can then be made between populations, which can be applied to the whole brain or specific regions of interest (ROIs). More recently, tract-based spatial statistics (TBSS) has been developed in which voxelbased diffusion metrics are projected onto an alignment-invariant tract representation (Smith et al., 2006). DTI is a relatively new technique and many of the early studies summarized here evaluate relatively small groups of mainly chronic schizophrenia patients.

\section{CHRONIC PATIENTS}

In patients with chronic schizophrenia, decreased FA within prefrontal and temporal lobes, as well as abnormalities within the fiber bundles connecting these regions, particularly the uncinate fasciculus and the cingulum bundle as well as the corpus callosum and internal capsule, are the most frequent positive findings (Figure 1). An earlier review of the literature reported that white matter in the frontal and temporal lobes were the most frequently

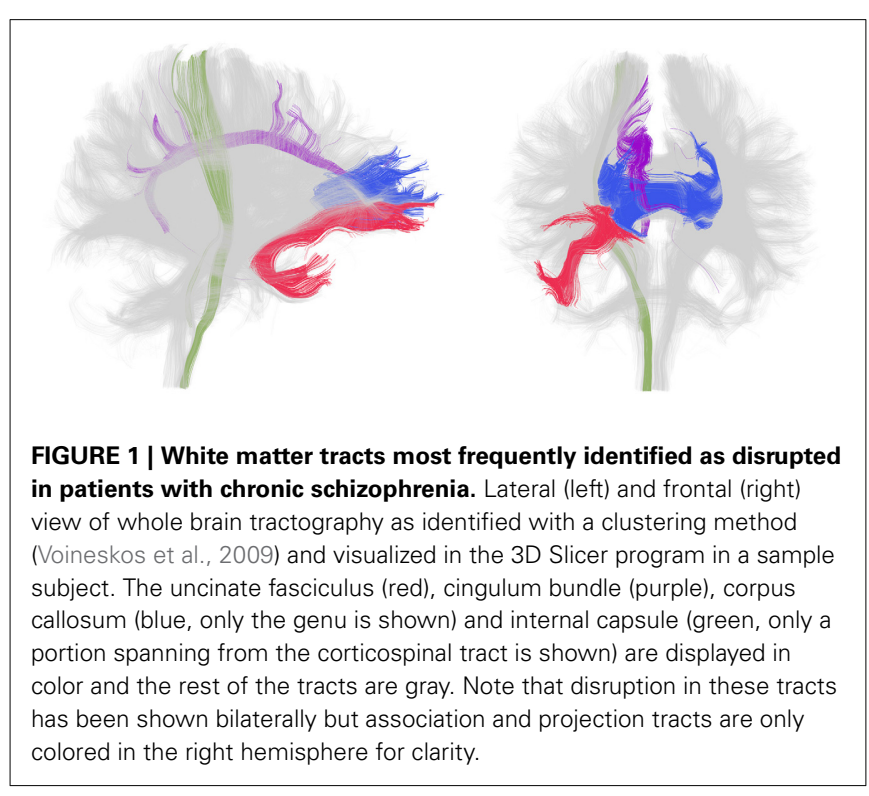

reported areas showing reduced FA in DTI studies of schizophrenia (Pettersson-Yeo et al., 2011). More recent studies support this with VBM (Walther et al., 2011) and TBSS (Scheel et al., 2012; Roalf et al., 2013; Fujino et al., 2014) analyses reporting decreased FA in frontal and temporal regions, as well as in the parietal and occipital cortices. Moreover, a meta analysis of 15 voxel based DTI studies in schizophrenia determined that significant reductions were present in two regions: the left frontal deep white matter and the left temporal deep white matter (Ellison-Wright and Bullmore, 2009). Reduced FA has also been described in superficial white matter in the left posterior parieto-occipital cortex and the left frontal lobe (Nazeri et al., 2013). White matter tracts interconnecting the frontal lobe, thalamus and cingulate gyrus traverse the frontal lobe and tracts interconnecting the frontal lobe, insula, hippocampus-amygdala, temporal and occipital lobes traverse the temporal lobe.

A reduction in FA has been shown in specific association, commissural and projection white matter tracts in chronic patients with schizophrenia (Table 1). Diffusion abnormalities identified in the arcuate fasciculus are predominantly in the left hemisphere though two studies have reported increased, rather than decreased, FA in this tract in schizophrenia patients relative to control subjects (Rotarska-Jagiela et al., 2009; Knochel et al., 2012). The corpus callosum is the largest white matter structure in the brain and is the main commissural tract as it connects the two hemispheres. Some studies find anisotropy differences in schizophrenia patients restricted to the anterior portion that connects the left and right prefrontal cortex, known as the genu (Hubl et al., 2004; Shergill et al., 2007; Kubicki et al., 2008).

As opposed to tract specific differences, several studies have reported widespread diffusion abnormalities in all tested regions (Lim et al., 1999; Minami et al., 2003; Reading et al., 2011; Schneiderman et al., 2011; Knochel et al., 2012), though not all DTI studies report positive findings when examining differences between schizophrenia patients and healthy controls. Two early studies showed no anisotropy differences in small samples of schizophrenia patients (Steel et al., 2001; Foong et al., 2002). A TBSS study found no differences in FA in a small sample of childhood-onset schizophrenia patients (Clark et al., 2012). Additionally, a recent tractography study reported no anisotropy differences in young adult patients with schizophrenia (Boos et al., 2012). A 2005 review of 15 DTI studies comparing schizophrenia patients to healthy controls concluded that, when the same ROI was investigated in different studies, as many failed to find a difference between groups as found one (Kanaan et al., 2005). Furthermore, a limitation of ROI studies is that the focus on one or a few specific structures neglects the rest of the brain. In an attempt to address this limitation, a brain-wide voxel wise meta-analysis and meta-regression analysis determined that decreased FA was restricted to interhemispheric fibers, anterior thalamic radiation, inferior longitudinal fasciculi, inferior frontal occipital fasciculi, cingulum and fornix (Bora et al., 2011). Overall, the above review of DTI findings in chronic patients with schizophrenia demonstrates that white matter abnormalities in chronic schizophrenia likely do exist. However, whether these abnormalities are localized to specific tracts, or spread throughout the brain is less clear. It appears that rather than specific 
Table 1 | White matter tract alterations in patients with chronic schizophrenia.

\begin{tabular}{|c|c|c|}
\hline White matter tract & Method & References \\
\hline \multirow[t]{3}{*}{ Uncinate fasciculus } & VBM & $\begin{array}{l}\text { Burns et al., 2003; Hubl et al., } \\
\text { 2004; Mori et al., 2007; } \\
\text { Munoz Maniega et al., 2008; } \\
\text { Sussmann et al., } 2009\end{array}$ \\
\hline & TBSS & $\begin{array}{l}\text { Seal et al., 2008; Knochel } \\
\text { et al., } 2012\end{array}$ \\
\hline & Tractography & $\begin{array}{l}\text { Voineskos et al., 2010; de } \\
\text { Weijer et al., 2011; Kunimatsu } \\
\text { et al., } 2012\end{array}$ \\
\hline \multirow[t]{3}{*}{ Cingulum bundle } & VBM & $\begin{array}{l}\text { Kubicki et al., 2003, 2005; Sun } \\
\text { et al., 2003; Wang et al., 2004; } \\
\text { Fujiwara et al., 2007; Mori } \\
\text { et al., 2007; Skelly et al., 2008; } \\
\text { Segal et al., } 2010\end{array}$ \\
\hline & TBSS & $\begin{array}{l}\text { Camchong et al., 2011; } \\
\text { Knochel et al., 2012; Yan et al., } \\
2012\end{array}$ \\
\hline & Tractography & $\begin{array}{l}\text { Manoach et al., 2007; } \\
\text { Voineskos et al., 2010; } \\
\text { Abdul-Rahman et al., 2011; de } \\
\text { Weijer et al., 2011; Kunimatsu } \\
\text { et al., } 2012\end{array}$ \\
\hline \multirow[t]{2}{*}{$\begin{array}{l}\text { Superior longitudinal } \\
\text { fasciculus }\end{array}$} & VBM & $\begin{array}{l}\text { Buchsbaum et al., 2006; Seok } \\
\text { et al., 2007; Shergill et al., } \\
\text { 2007; Skelly et al., 2008; } \\
\text { Rotarska-Jagiela et al., 2009; } \\
\text { Nakamura et al., } 2012\end{array}$ \\
\hline & TBSS & $\begin{array}{l}\text { Karlsgodt et al., 2008; Seal } \\
\text { et al., 2008; Knochel et al., } \\
2012\end{array}$ \\
\hline \multirow[t]{2}{*}{ Arcuate fasciculus } & VBM & $\begin{array}{l}\text { Burns et al., 2003; Hubl et al., } \\
\text { 2004; Kubicki et al., 2005; } \\
\text { Munoz Maniega et al., } 2008\end{array}$ \\
\hline & Tractography & $\begin{array}{l}\text { Phillips et al., 2009; Catani } \\
\text { et al., 2011; de Weijer et al., } \\
2011\end{array}$ \\
\hline \multirow[t]{2}{*}{$\begin{array}{l}\text { Inferior longitudinal } \\
\text { fasciculus }\end{array}$} & VBM & $\begin{array}{l}\text { Hubl et al., 2004; Shergill } \\
\text { et al., 2007; Friedman et al., } \\
\text { 2008; Skelly et al., 2008; } \\
\text { Rotarska-Jagiela et al., } 2009\end{array}$ \\
\hline & Tractography & Phillips et al., 2009 \\
\hline \multirow[t]{2}{*}{$\begin{array}{l}\text { Occipital frontal } \\
\text { fasciculi }\end{array}$} & VBM & $\begin{array}{l}\text { Kubicki et al., 2005; Skelly } \\
\text { et al., 2008; Rotarska-Jagiela } \\
\text { et al., 2009; Nakamura et al., } \\
2012\end{array}$ \\
\hline & TBSS & $\begin{array}{l}\text { Seal et al., 2008; Knochel } \\
\text { et al., } 2012\end{array}$ \\
\hline
\end{tabular}

(Continued)
Table 1 | Continued

\begin{tabular}{|c|c|c|}
\hline White matter tract & Method & References \\
\hline \multirow[t]{2}{*}{ Fornix } & VBM & Kubicki et al., 2005 \\
\hline & Tractography & $\begin{array}{l}\text { Abdul-Rahman et al., 2011; } \\
\text { Kunimatsu et al., } 2012\end{array}$ \\
\hline \multirow[t]{3}{*}{ Corpus callosum } & VBM & $\begin{array}{l}\text { Foong et al., 2000; Hubl et al., } \\
\text { 2004; Kubicki et al., 2005; } \\
\text { Buchsbaum et al., 2006; Mori } \\
\text { et al., 2007; Shergill et al., } \\
\text { 2007; Rotarska-Jagiela et al., } \\
\text { 2008, 2009; Kitis et al., 2011; } \\
\text { Kong et al., } 2011\end{array}$ \\
\hline & TBSS & $\begin{array}{l}\text { Knochel et al., 2012; Roalf } \\
\text { et al., 2013; Fujino et al., } 2014\end{array}$ \\
\hline & Tractography & $\begin{array}{l}\text { Kubicki et al., 2008; Kong } \\
\text { et al., } 2011\end{array}$ \\
\hline Anterior commissure & Tractography & Choi et al., 2011 \\
\hline \multirow[t]{3}{*}{ Internal capsule } & VBM & $\begin{array}{l}\text { Kubicki et al., 2005; } \\
\text { Buchsbaum et al., 2006; } \\
\text { Munoz Maniega et al., 2008; } \\
\text { Skelly et al., 2008; Sussmann } \\
\text { et al., 2009; Nakamura et al., } \\
\text { 2012; Levitt et al., } 2012\end{array}$ \\
\hline & Tractography & $\begin{array}{l}\text { Oh et al., 2009; Rosenberger } \\
\text { et al., } 2012\end{array}$ \\
\hline & TBSS & $\begin{array}{l}\text { Seal et al., 2008; Knochel } \\
\text { et al., } 2012\end{array}$ \\
\hline \multirow[t]{2}{*}{ Cortico-spinal tract } & TBSS & Knochel et al., 2012 \\
\hline & Tractography & de Weijer et al., 2011 \\
\hline \multirow[t]{2}{*}{ Corona radiata } & VBM & Cui et al., 2011 \\
\hline & TBSS & Fujino et al., 2014 \\
\hline $\begin{array}{l}\text { Middle cerebellar } \\
\text { peduncles }\end{array}$ & VBM & Okugawa et al., 2004 \\
\hline
\end{tabular}

tracts being affected, there is more likely an array of subtly altered networks distributed throughout the brain. Nevertheless, it could also be argued that the data suggest that the connectivity of frontal regions is particularly affected. This variability among studies with many white matter tracts seemingly affected, and difficulties in replicating findings is consistent with the conclusions of two recent reviews of DTI studies of schizophrenia (Melonakos et al., 2011; Fitzsimmons et al., 2013).

\section{FIRST EPISODE PATIENTS}

Neuroimaging studies of patients with schizophrenia who are experiencing their first episode of psychosis can help to tease apart more definitively what is an intrinsic marker of the disorder, and what is a secondary effect of the illness. The main advantage of such studies is that the effects of long-term medication 
and chronicity can be ruled out as possible confounds. Concern about brain abnormalities being a result of treatment rather than being associated with the disease itself stem from studies that show that antipsychotic treatment is associated with smaller brain volumes in patients (Ho et al., 2011) and rodents (Vernon et al., 2011). The criteria for first episode subjects can be somewhat variable between studies but first episode patients are typically defined as being within 3 years of the onset of the first episode of psychosis. Some of these studies specifically examine patients that have never taken antipsychotic medications. DTI studies that examine first episode patients ask, are white matter abnormalities already present at illness onset?

In first episode patients evidence exists for tract specific white matter abnormalities in many of the same tracts identified in chronic patients, though findings are less consistent (Table 2). In contrast to tract specific differences, widespread DTI based changes throughout the brain have been reported in several studies of first episode schizophrenia subjects. In studies where patients have had minimal exposure to antipsychotic medications (i.e., weeks) VBM has revealed diffuse patterns of diffusion alterations in frontal, parietal and temporal lobes (Szeszko et al., 2005; Federspiel et al., 2006; Hao et al., 2006; Peters et al., 2009). A voxel wise meta analysis reported FA reductions in the white matter of the right deep frontal and left deep temporal lobes in first episode patients relative to healthy controls (Yao et al., 2013). Overall reduction in white matter tissue has been also been reported (Mendelsohn et al., 2006). In TBSS (Ruef et al., 2012; Lee et al., 2013) and tractography (Rathi et al., 2011) studies where patients were ill for 1 year or less on average and in one TBSS study of drug-naïve patients (Filippi et al., 2014) differences between patients and controls were present in white matter tracts throughout the brain. Free-water imaging - a recently developed methodology that can be applied to diffusion MRI data to distinguish neuroinflamation effects from axonal degeneration-has suggested that inflammation is widespread but axonal degeneration limited to focal areas in the frontal lobe white matter in first episode patients (Pasternak et al., 2012). In contrast, several other studies that have found no differences in all regions assessed in first episode samples of patients compared to healthy individuals, including those with minimal (Price et al., 2005, 2008; Friedman et al., 2008; Qiu et al., 2009; White et al., 2009) or no (Zou et al., 2008) antipsychotic medication use. Some studies found no FA abnormalities in first episode patients, but did identify possible abnormalities with other diffusion indices (Mendelsohn et al., 2006; Price et al., 2008; Chan et al., 2010; Moriya et al., 2010).

In summary, studies that identify differences between first episode patients and healthy controls suggest that DTI abnormalities are present in the early phase of schizophrenia. Studies that identify differences in medication naïve first episode patients support that these differences are not due to medication effects on the brain because they precede treatment. These results vary considerably between studies, currently no white matter tracts have been consistently identified though many studies have reported positive finding in the uncinate fasciculus. When taken together, the evidence suggests that DTI abnormalities in first-episode patients are less consistent than in chronic patients though this may be because some of these studies are underpowered, having small sample sizes because these patients are more difficult to recruit.
Table 2 | White matter tract alterations in first episode and medication naïve patients with schizophrenia.

\begin{aligned} \hline White matter tract Patient type & $\begin{array}{l}\text { Comparison References } \\ \text { to healthy } \\ \text { subjects }\end{array}\end{aligned}$

Uncinate fasciculus First episode Difference Price et al., 2008,

Szeszko et al., 2008;

Kawashima et al.,

2009; Peters et al.,

2009; Luck et al.,

2011; Mandl et al.,

2012; Lee et al., 2013

\begin{tabular}{llll}
\hline $\begin{array}{l}\text { Superior longitudinal } \\
\text { and arcuate fasciculi }\end{array}$ & First episode Difference & Federspiel et al., \\
& & & 2006; Szeszko et al., \\
& & 2008; Guo et al., \\
& & $2012 ;$ Mandl et al., \\
& & 2012 \\
\cline { 2 - 3 } & & & \\
& Medication & Difference & Perez-lglesias et al., \\
naive & & 2010
\end{tabular}

Arcuate fasciulus First episode No difference Peters et al., 2008

Cingulum bundle First episode Difference Federspiel et al.,

2006; Hao et al.,

2006; Lee et al.,

2013

First episode No difference Peters et al., 2008;

Kawashima et al.,

2009; Luck et al.,

2011

Genu of the corpus First episode Difference Price et at 2007 .

callosum

Henze et al., 2012:

Lee et al., 2013

\begin{tabular}{|c|c|c|}
\hline $\begin{array}{l}\text { Medication } \\
\text { naive }\end{array}$ & Difference & $\begin{array}{l}\text { Perez-Iglesias et al., } \\
2010\end{array}$ \\
\hline
\end{tabular}

First episode No difference Price et al., 2005;

Cheung et al., 2008;

Friedman et al.,

2008; Peters et al.,

2008; Gasparotti

et al., 2009; Kong

et al., 2011

\begin{tabular}{ll}
\hline Medication No difference & Cheung et al., 2008; \\
naive & Gasparotti et al., \\
& 2009
\end{tabular}

Splenium of the

First episode Difference Federspiel et al.,

corpus callosum 2006; Dekker et al., 2010

\begin{tabular}{|c|c|c|}
\hline $\begin{array}{l}\text { Medication } \\
\text { naive }\end{array}$ & Difference & $\begin{array}{l}\text { Cheung et al., } 2008 \\
\text { Gasparotti et al., } \\
2009\end{array}$ \\
\hline First episode & No difference & $\begin{array}{l}\text { Price et al., 2005, } \\
\text { 2007; Friedman } \\
\text { et al., 2008; Peters } \\
\text { et al., } 2008\end{array}$ \\
\hline
\end{tabular}

(Continued) 
Table 2 | Continued

\begin{tabular}{|c|c|c|c|}
\hline White matter tract & Patient type & $\begin{array}{l}\text { Comparison } \\
\text { to healthy } \\
\text { subjects }\end{array}$ & References \\
\hline \multirow[t]{4}{*}{ Internal capsule } & First episode & Difference & $\begin{array}{l}\text { Federspiel et al., } \\
\text { 2006; Cheung et al., } \\
\text { 2008; Perez-Iglesias } \\
\text { et al., 2010; Guo } \\
\text { et al., 2012; Lee } \\
\text { et al., } 2013\end{array}$ \\
\hline & First episode & No difference & Lee et al., 2012 \\
\hline & $\begin{array}{l}\text { Medication } \\
\text { naive }\end{array}$ & Difference & $\begin{array}{l}\text { Perez-Iglesias et al., } \\
2010\end{array}$ \\
\hline & $\begin{array}{l}\text { Medication } \\
\text { naive }\end{array}$ & No difference & Zou et al., 2008 \\
\hline \multirow{3}{*}{$\begin{array}{l}\text { Inferior longitudinal } \\
\text { fasciculus }\end{array}$} & First episode & Difference & Chan et al., 2010 \\
\hline & $\begin{array}{l}\text { Medication } \\
\text { naive }\end{array}$ & Difference & $\begin{array}{l}\text { Cheung et al., 2008; } \\
\text { Perez-Iglesias et al., } \\
\text { 2010; Liu et al., } 2013\end{array}$ \\
\hline & First episode & No difference & Friedman et al., 2008 \\
\hline \multirow[t]{2}{*}{$\begin{array}{l}\text { Occipital-frontal } \\
\text { fasciculus }\end{array}$} & First episode & Difference & $\begin{array}{l}\text { Szeszko et al., 2008; } \\
\text { Lee et al., } 2013\end{array}$ \\
\hline & $\begin{array}{l}\text { Medication } \\
\text { naive }\end{array}$ & Difference & $\begin{array}{l}\text { Cheung et al., 2008; } \\
\text { Perez-Iglesias et al., } \\
\text { 2010; Liu et al., } 2013\end{array}$ \\
\hline Optic radiations & First episode & Difference & Henze et al., 2012 \\
\hline Fornix & First episode & Difference & $\begin{array}{l}\text { Guo et al., 2012; Lee } \\
\text { et al., } 2013\end{array}$ \\
\hline
\end{tabular}

\section{HIGH-RISK SUBJECTS}

In order to determine what brain abnormalities are present prior to illness onset, studies have examined people who are at high risk for developing schizophrenia. By following high-risk individuals and examining structural differences between those who go on to develop the disease and those who do not, this approach attempts to identify structural abnormalities that either predict future illness or act as indicators of resilience to developing schizophrenia. Different strategies have been employed to identify subjects at high risk for developing schizophrenia. In the Edinburgh high risk study, young asymptomatic subjects have at least two first- or second-degree relatives with a confirmed diagnosis of schizophrenia; more than half of these subjects developed psychotic symptoms within the first 5 years and $13 \%$ of this cohort went on to develop schizophrenia (Lawrie et al., 2008). The Melbourne ultra-high risk studies identified symptomatic, clinically compromised and help seeking individuals at risk of developing a florid psychosis, $30-40 \%$ of these subjects transition to psychosis in 12 months (Pantelis et al., 2007). Unlike studies in patients with schizophrenia, brain abnormalities in high-risk subjects cannot be attributed to secondary effects of the illness (i.e., neurotoxic effects of psychosis) or its treatment (i.e., medication effects). However, these high-risk subjects often already have attenuated psychotic symptoms, depressive symptoms, anxiety and other symptoms that may complicate interpretation of neuroimaging results. It should also be noted that differences in the nature of high-risk samples make it difficult to directly compare results between studies.

Two TBSS studies found altered DTI indices in high-risk subjects in the superior longitudinal fasciculus (Karlsgodt et al., 2009; Clemm von Hohenberg et al., 2014), a finding that was replicated in a voxel-based study that found intermediate FA values in high-risk subjects compared to a first episode group and controls in the this tract (Carletti et al., 2012). Differences in the corpus callosum, and posterior corona radiata have also been replicated (Carletti et al., 2012; Clemm von Hohenberg et al., 2014). Additionally, reduced FA has been found in left inferior longitudinal fasciculus, left inferior fronto-occipital fasciculus, right external capsule and right internal capsule in high-risk subjects (Carletti et al., 2012). A VBM study reported reduced FA in the superior frontal gyrus in high-risk subjects compared to healthy controls (Peters et al., 2009), though the same researchers failed to find differences between white matter tracts in these groups with tractography methods (Peters et al., 2008). In a longitudinal follow-up of the same sample, no differences were found between high-risk subjects who transitioned to psychosis and subjects that did not transition (Peters et al., 2010). Others did identify some DTI based differences in high-risk subjects who transitioned to psychosis compared to those who did not transition to psychosis, with lower FA lateral in the right putamen and in the left superior temporal lobe, and higher FA in the left medial temporal lobe (Bloemen et al., 2009). Finally, another study identified a reduction in FA in high-risk patients in left frontal white matter in those who developed psychosis, which was not evident in those who did not transition to psychosis (Carletti et al., 2012). These studies implicate alterations in these white matter regions early in the illness, which typically spans late adolescence and early adulthood. It is of note that the most consistent finding, changes in the superior longitudinal fasciculus, is a tract that is particularly dynamic in its development during this period in healthy subjects (Peters et al., 2012). These active changes that are occurring before and around the time of illness onset could potentially be ameliorated by early therapeutic interventions.

\section{FAMILY STUDIES}

Another group of subjects who are of interest in brain imaging studies of schizophrenia are unaffected family members of patients with schizophrenia, most commonly siblings. Unaffected siblings share approximately $50 \%$ of the genome of the affected relative. DTI studies in schizophrenia patients that include a group of first-degree relatives attempt to characterize the extent to which differences in DTI metrics might reflect a genetic predisposition to schizophrenia through the identification of shared white matter abnormalities. In both schizophrenia patients and their first-degree relatives, reduced FA has been found in white matter associated in the left prefrontal cortex and in the medial temporal lobe, but not in the anterior cingulate cortex (Hao 
et al., 2009). One study focused on the frontal lobe and identified shared differences between patients and first-degree relatives in the medial frontal regions (Camchong et al., 2009). FA was shown to vary in accordance with relatedness to a patient in superficial white matter in the temporal and occipital lobes (Phillips et al., 2011). Additionally, a voxel-based study found reduced FA in first degree relatives compared to controls in inferior frontal, posterior cingulate, angular white matter, and increased FA in pontine tegmental, right superior frontal gyri and in the anterior cingulate (Hoptman et al., 2008). Tract specific analyses found differences in patients and relatives in the anterior limb of the internal capsule, but not the uncinate and the arcuate fasciculi (Munoz Maniega et al., 2008), and in the inferior fronto-occipital fasciculus, left inferior longitudinal fasciculus, and left temporal superior fasciculus (Clark et al., 2011). TBSS analysis in firstdegree relatives of schizophrenia patients showed intermediate values between patients and controls in the inferior frontooccipital fasciculus, superior longitudinal fasciculus, uncinate fasciculus, arcuate fasciculus and cingulum bundle (Knochel et al., 2012). FA alterations in these regions that are shared between patients and relatives may reflect a genetic liability of schizophrenia, though it will be important to see further replication of these results.

\section{STRUCTURAL CO-VARIANCE}

Relationships between volumetric or cortical thickness measures in different regions have been used to investigate associations between brain regions. A straightforward version of this type of analysis has shown that schizophrenia is associated with differences in the bilateral symmetry of regions. Exaggeration of leftward thalamic asymmetry (Csernansky et al., 2004), reduced laterality in planum temporale (Ratnanather et al., 2013) and hippocampus (Kim et al., 2005) and reversal of the normal asymmetry of the inferior parietal cortex (Niznikiewicz et al., 2000; Buchanan et al., 2004) have been reported in schizophrenia patients. Examination of inter-regional structural co-variance can also be used to describe anatomical connectivity or coupling between brain regions, based on the principle that anatomically connected regions share common trophic factors and correlate in size (Alexander-Bloch et al., 2013). In these analyses correlations in interregional gray-matter volume or cortical thickness are computed in a group of subjects. Several studies have identified structural co-variance differences in schizophrenia patients compared to healthy control subjects with these methods (Table 3). Both strengthened (Breier et al., 1992; Wible et al., 1995, 2001; Mitelman et al., 2005b,c) and attenuated (Woodruff et al., 1997; Bullmore et al., 1998; Wright et al., 1999) co-variance between volumetric measures of the prefrontal and temporal cortex as well as stronger fronto-parietal relationships (Niznikiewicz et al., 2000; Buchanan et al., 2004; Abbs et al., 2011) have been described in patients. Additionally, altered cortico-thalamic (Portas et al., 1998; Mitelman et al., 2005a, 2006) and enhanced interhemisphereic prefrontal (Wheeler et al., 2014) structural co-variance have been reported in schizophrenia patients. Enhanced coupling within the default mode network and between default mode regions and the frontal cortex have been described in high-risk subjects (Bhojraj et al., 2010).
Additionally, altered structural covariance within subgroups of schizophrenia patients has also been described. There is not a clear interpretation of the neural basis of schizophrenia-related changes in structural co-variance. Enhanced correlations may be related to overconnectivity, coordinated gray matter loss or a lack of developmental specificity, whereas diminished correlations between brain regions may suggest disconnectivity or localized degeneration.

\section{NETWORK ANALYSES}

Network-based analyses may provide a characteristic neural signature of illness in schizophrenia. Recently, methods of measuring structural brain connectivity have been used to comprehensively map the large-scale architecture of connectivity in the brain by quantifying pair-wise interactions between regions throughout the brain (Sporns, 2011). Graph theory-a branch of mathematics that is used to study and describe all types of networks - can be used to compute various organizational properties of brain-wide connectivity ${ }^{193}$ (Figure 2). A large appeal graph theory rests in its ability to provide relatively succinct, characterizations of regional and whole-brain disturbances in brain network connectivity and topology ${ }^{195}$.

Altered connectivity and brain network topology has been described in the brains of schizophrenia patients (Table 4). Structural connectomic studies have identified altered connectivity within sub-networks in chronic patients (Skudlarski et al., 2010; Zalesky et al., 2011; Collin et al., 2013), as well as first episode medication naïve patients (Zhang et al., 2014) and siblings of patients (Collin et al., 2014). Graph theoretical analyses at the whole network level have predominantly identified equivalent small-world organization (Bassett et al., 2008; van den Heuvel et al., 2010, 2013; Zalesky et al., 2011; Wang et al., 2012; Zhang et al., 2014) and network inefficiency with reduced integration between regions in chronic patients (Bassett et al., 2008; van den Heuvel et al., 2010; Zalesky et al., 2011; Wang et al., 2012; Zhang et al., 2012b; Ottet et al., 2013), first episode medication naïve patients (Zhang et al., 2014), unaffected siblings (Collin et al., 2014) and high-risk infants (Shi et al., 2012). At the regional level network studies have provided strong evidence for reorganization of network hubs in the brains of schizophrenia patients (Rubinov and Bullmore, 2013), commonly with a reduction of these regions localized to the frontal cortex and limbic areas (Bassett et al., 2008; van den Heuvel et al., 2010; Shi et al., 2012; Wang et al., 2012; Zhang et al., 2012b; Ottet et al., 2013; Collin et al., 2014) including in the study of first episode medication naïve patients (Zhang et al., 2014). Additionally, reduced connectivity between frontal and parietal hubs has been described in schizophrenia patients and their unaffected siblings (van den Heuvel et al., 2013; Collin et al., 2014). Though DTIbased structural connectivity and morphometry-based structural co-variance are related to each other (Gong et al., 2012), interpretation of results from these two types of studies can be distinct. Despite methodological differences many of the above-described global results from network analyses in schizophrenia patients are consistent. However, localized results of altered network properties in specified brain systems are much more varied between studies. 
Table 3 | Structural co-variance comparisons in patients with schizophrenia.

\begin{tabular}{|c|c|c|c|c|c|}
\hline Study & Subjects & $\begin{array}{l}\text { Relationships } \\
\text { examined } \\
\text { (\# subregions) }\end{array}$ & Analysis & Results SCZ > HC & Results HC > SCZ \\
\hline Wible et al., 1995 & $\begin{array}{l}14 \mathrm{SCZ} \\
15 \mathrm{HC}\end{array}$ & PFC (2) <-> temporal (6) & $\begin{array}{l}\text { Interregional } \\
\text { volume correlation }\end{array}$ & $\begin{array}{l}\text { L PFC GM }<->L \text { ant } \\
\text { HPC/AMY; L ant-PHG; } \\
\text { L ant-STG } \\
\text { L ant-PFC WM <-> } \\
\text { L ant-STG } \\
\text { R PFC WM <-> } \\
\text { R post-HPC/AMY } \\
\text { Among HPC/AMY, PHG, } \\
\text { STG }\end{array}$ & $\begin{array}{l}\text { L PFC GM <-> } \\
\text { post-HPC/AMY }\end{array}$ \\
\hline Bullmore et al., 1998 & $\begin{array}{l}35 \mathrm{SCZ} \\
35 \mathrm{HC}\end{array}$ & $\begin{array}{l}\text { PFC }(2)<->\text { temporal } \\
(3)<->\text { CG (2) }\end{array}$ & $\begin{array}{l}\text { Interregional } \\
\text { volume regression }\end{array}$ & & $\begin{array}{l}\text { PFC }->S^{*} G^{*} \\
\text { STG }->\text { PFC }->H_{P C}^{*}\end{array}$ \\
\hline Portas et al., 1998 & $\begin{array}{l}15 \mathrm{SCZ} \\
15 \mathrm{HC}\end{array}$ & $\begin{array}{l}\text { THAL<->PFC; CG; } \\
\text { striatum; HPC; AMY; STG }\end{array}$ & $\begin{array}{l}\text { Interregional } \\
\text { volume correlation }\end{array}$ & $\begin{array}{l}\text { THAL }<->\text { ventricle [neg] } \\
\text { THAL }<->\text { L frontal WM }\end{array}$ & THAL $<->$ L SFG [neg] \\
\hline Wright et al., 1999 & $\begin{array}{l}27 \mathrm{SCZ} \\
37 \mathrm{HC}\end{array}$ & $\begin{array}{l}\text { Among: GM (92); } \\
\text { ventricles (12) }\end{array}$ & Principle component & $\begin{array}{l}\text { 1st component (global } \\
\text { GM <-> ventricles)* } \\
\text { 4th component } \\
\text { (frontal<->temporal)* }^{*}\end{array}$ & \\
\hline $\begin{array}{l}\text { Buchanan et al., } \\
2004\end{array}$ & $\begin{array}{l}44 \mathrm{SCZ} \\
34 \mathrm{HC}\end{array}$ & $\begin{array}{l}\text { Among: PFC (4); STG; } \\
\text { IPL (2) }\end{array}$ & $\begin{array}{l}\text { Interregional volume } \\
\text { correlation }\end{array}$ & $\begin{array}{l}L \text { and } R I F G<->L \text { and } R \\
A G^{*}\end{array}$ & \\
\hline $\begin{array}{l}\text { Mitelman et al., } \\
\text { 2005a }\end{array}$ & $\begin{array}{l}106 \mathrm{SCZ} \\
42 \mathrm{HC}\end{array}$ & $\begin{array}{l}\text { THAL(5) <-> Broadmann } \\
\text { areas (39) }\end{array}$ & $\begin{array}{l}\text { Interregional volume } \\
\text { correlation }\end{array}$ & & $\begin{array}{l}\text { R THAL <-> R PFC; } \\
\text { R MTG* } \\
\text { L THAL<-> L PFC; L CG; } \\
\text { L post-parietal; occipital* }\end{array}$ \\
\hline $\begin{array}{l}\text { Mitelman et al., } \\
2005 b\end{array}$ & $\begin{array}{l}106 \mathrm{SCZ} \\
42 \mathrm{HC}\end{array}$ & $\begin{array}{l}\text { Frontal }(11)<->\text { other } \\
\text { Broadmann areas }(39)\end{array}$ & $\begin{array}{l}\text { Interregional volume } \\
\text { correlation }\end{array}$ & $\begin{array}{l}\text { Frontal <->temporal; } \\
\text { parietal; occipital }\end{array}$ & Among frontal* \\
\hline $\begin{array}{l}\text { Mitelman et al., } \\
2005 c\end{array}$ & $\begin{array}{l}106 \mathrm{SCZ} \\
42 \mathrm{HC}\end{array}$ & $\begin{array}{l}\text { Temporal }(12)<->\text { other } \\
\text { Broadmann areas (39) }\end{array}$ & $\begin{array}{l}\text { Interregional volume } \\
\text { correlation }\end{array}$ & Frontal $<->$ temporal* & $\begin{array}{l}\text { Frontal }<->\text { temporal } \\
\text { [neg] }^{*} \\
\text { R temporal pole }<-> \\
\text { other temporal }^{*}\end{array}$ \\
\hline Mitelman et al., 2006 & $\begin{array}{l}41 \mathrm{SCZ} \\
\text { (unmedicated) } \\
59 \mathrm{HC}\end{array}$ & $\begin{array}{l}\text { THAL(3) <-> Broadmann } \\
\text { areas (39) }\end{array}$ & $\begin{array}{l}\text { Interregional volume } \\
\text { correlation }\end{array}$ & $\begin{array}{l}\text { Pulvinar <-> DLPFC; } \\
\text { temporal [neg] }\end{array}$ & $\begin{array}{l}\text { R pulvinar <-> R OFC; } \\
\text { R occipital* } \\
\text { Centromedian nucleus } \\
<->\text { DLPFC* }\end{array}$ \\
\hline
\end{tabular}


Table 3 | Continued

\begin{tabular}{|c|c|c|c|c|c|}
\hline Study & Subjects & $\begin{array}{l}\text { Relationships } \\
\text { examined } \\
\text { (\# subregions) }\end{array}$ & Analysis & Results SCZ > HC & Results $\mathrm{HC}>\mathrm{SCZ}^{\#}$ \\
\hline Abbs et al., 2011 & $\begin{array}{l}88 \mathrm{SCZ} \\
48 \mathrm{HC}\end{array}$ & $\begin{array}{l}\text { Among PFC; IPL; ant CG; } \\
\text { PHG; HPC }\end{array}$ & $\begin{array}{l}\text { Interregional volume } \\
\text { correlation }\end{array}$ & $\begin{array}{l}\mathrm{HPC}<->\text { ant-CG [neg] (in } \\
\mathrm{F} \text { only)* } \\
\mathrm{IPL}<->\text { ant-CG (in F } \\
\text { only)* }\end{array}$ & \\
\hline Wheeler et al., 2014 & $\begin{array}{l}54 \mathrm{SCZ} \\
68 \mathrm{HC}\end{array}$ & $\begin{array}{l}\text { L DLPFC <-> cortex (81, } \\
923 \text { vertices) }\end{array}$ & $\begin{array}{l}\text { Interregional cortical } \\
\text { thickness correlation }\end{array}$ & $\begin{array}{l}\text { L DLPFC <-> R DLPFC; } \\
\text { R VMPFC* }\end{array}$ & \\
\hline
\end{tabular}

\footnotetext{
\# Results reported as significant positive correlations in one group and not the other unless indicated by [neg] in which case there are significant negative correlations in one group but not the other. Significant differences between groups are indicated by *.

SCZ, schizophrenia; HC, healthy control; ant, anterior; post, posterior; med, medial; lat, lateral; L, left; $R$, right; F, female.

Symbol: <->, between.

Brain regions: $A G$, angular gyrus; $A M Y$, amygdala; $C G$, cingulate gyrus; DLPFC, dorsal lateral prefrontal cortex; GM, gray matter; HPC, hippocampus; IFG, inferior frontal gyrus; IPL, inferior parietal; Ins, Insular cortex; ITG, inferior temporal gyrus; MTG, middle temporal gyrus; OFC, orbital frontal cortex; PCUN, precuneus; PFC, prefrontal cortex; PHG. parahippocampal gyrus; SFG, superior frontal gyrus; STG, superior temporal gyrus; THAL, thalamus; VLPFC, ventral lateral prefrontal cortex; VMPFC, ventral medial prefrontal cortex; WM, white matter.
}

\section{HETEROGENEITY OF FINDINGS}

Neuroimaging investigations in schizophrenia have produced a large body of evidence for structural connectivity abnormalities associated with the illness. It is clear from this review of the literature that there is considerable variability among white matter tract investigations in chronic patients as well as in first episode patients, individuals at high risk to develop the illness and firstdegree family members, as well as in structural co-variance and network-based investigations. There are several likely contributing factors to this heterogeneity. First, methodological differences exist within imaging modalities, and the same dataset analyzed with different techniques may produce different results and therefore different conclusions. Second, a large contributing factor to the heterogeneity of results is due to the fact that the clinical presentation of schizophrenia itself is very heterogeneous. A number of studies that are presented here combine a range of schizophrenia diagnostic subtypes within their experimental cohort, including schizoaffective disorder, schizophreniform disorder and schizotypal personality disorder. Even within the diagnosis of schizophrenia, different subtypes of the illness have been proposed, such as the deficit subtype that describes patients with primary and enduring negative symptoms. The inclusion of different diagnostic categories within one experimental cohort makes any subsequent results inherently more difficult to interpret. Third, the causal mechanisms underlying schizophrenia are themselves heterogeneous, so brain abnormalities likely vary according to these and other genetic and environmental factors, as well as the developmental stage in which these occur. Finally, there is a large difference in moderator variables across studies such as age of onset, gender, chronicity, medication and parental socio-economic status, complicating the direct comparability of one study to another. For example, differences in FA have been reported between smoking and nonsmoking subjects (Cullen et al., 2012), which could potentially confound results if this detail is not accounted for in schizophrenia and control populations that are being compared. Moreover, it should be noted that identified morphological alterations are likely not specific to the diagnosis of schizophrenia. For example, substantial overlap in the localization of white matter FA reductions exists in schizophrenia and bipolar disorder (Sussmann et al., 2009). There are a number of other potential factors, such as variations in genes, which could lead to inconstant findings in these studies (Lett et al., 2013).

To address the influence of clinical heterogeneity of schizophrenia on brain connectivity, brain imaging metrics have been examined in relation to symptoms. Negative symptom severity has been associated with lower FA in the bilateral uncinate fasciculus and inferior frontal white matter (Wolkin et al., 2003; Szeszko et al., 2008). When comparing schizophrenia patients with the deficit syndrome to patients without the deficit syndrome and control subjects, deficit patients have been shown to have distinct DTI-based measures in the right inferior 


\section{(1) assess group}

$1 \mathrm{~A}$ brain parcellation

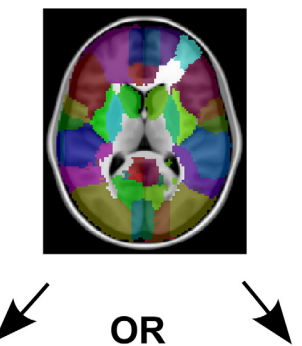

$1 \mathrm{~B}$

diffusion tensor imaging assess interregional connections

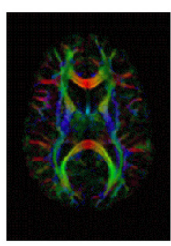

association matrices
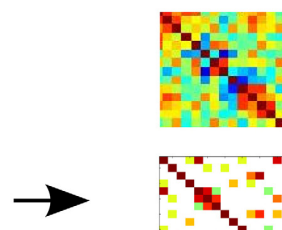

1C structural co-variance

assess interregional

corrrelations
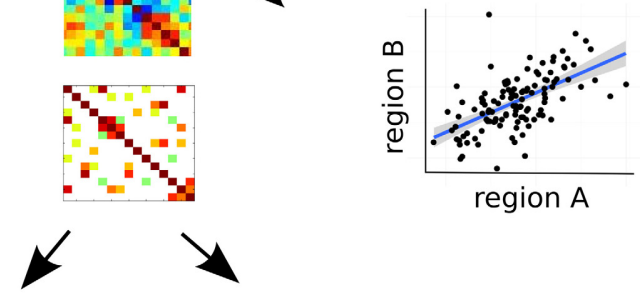

(3) graph theory analysis

3A evaluate network-wide organization

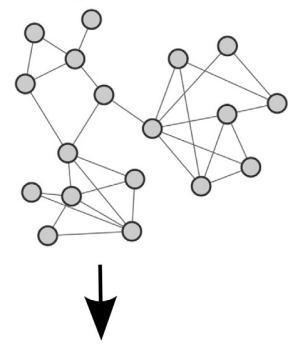

2 compare connectivity between groups
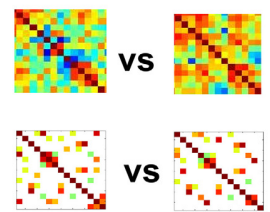

3B evaluate community structure

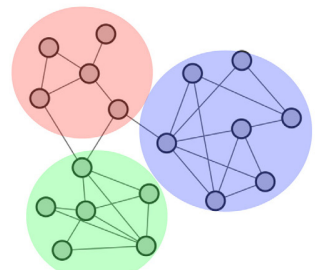

3C evaluate node and edge properties

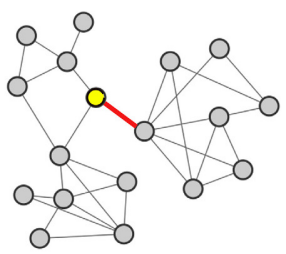

FIGURE 2 | Structural network analysis steps. (1) Assess group connectivity. Perform MRI imaging and parcellate the brain, many different methods can be applied (Craddock et al., 2013) (1A). Quantify DTI-based structural connectivity or morphometry-based structural co-variance throughout the brain. For DTI the presence and strength of interregional connections are assessed, one matrix is generated for each subject and then a group average is calculated (1B). For structural co-variance analysis between-subject correlations in morphology are calculated in each group
(1C). In each case associations are described with an association matrix whose rows and columns correspond to different brain regions. (2) Compare connectivity between groups. Statistical comparison can be done on a connection by connection basis with permutation testing or with Network Based Statistics (NBS), a statistical approach that is able to identify altered sub-networks while controlling the family wise error rate associated with testing for differences between a large number of connections

(Continued) 


\section{FIGURE 2 | Continued}

(Zalesky et al., 2010). (3) Graph theory analysis. Convert matrices to networks with collections of nodes (brain regions) interconnected by edges

(connections) (Bullmore and Sporns, 2009). Edges describe the degree of anatomical connectivity or coupling between network nodes and can be either weighted according to the strength of measured connectivity or unweighted and binary. Once networks are established, three basic types of graph theory measures can be assessed. First graph theory metrics can assess network-wide integration (characteristic path length, global efficiency) and segregation (mean clustering coefficient, mean local efficiency) as well as characterize network architecture (mean degree, degree distribution, mean connectivity, assortativity, hierarchy, small-world organization) (3A). Second, networks can be assessed for their modular structure, identifying distinct communities of nodes and connections that cluster together (3B). Third, at the level of individual regions and connections, nodes and edges can be assessed for centrality, which is thought to reflect the potential for enabling efficient communication in the network. These centrality measures are based on number of connections (degree) and positioning within the network (betweenness, eigenvector centrality, closeness). Hub regions in the brain that are thought to play more integral roles in network function due to their central positioning can be described with these centrality metrics (Rubinov and Bullmore, 2013) (3C). longitudinal fasciculus, right arcuate fasciculus, left uncinate fasciculus and right superior longitudinal fasciculus (Rowland et al., 2009; Kitis et al., 2012; Voineskos et al., 2013). One first episode study reported a negative correlation between FA values in the white matter adjacent to the right lateral ventricle and negative symptom scores and a positive correlation of FA values with positive symptom scores in the same brain region (Moriya et al., 2010). Similarly, increased FA in several regions was related to more severe positive symptoms as well as longer duration of untreated psychosis in a recent study (Filippi et al., 2014). Auditory hallucinations have been positively related to FA in the anterior corpus callosum, cingulum and superior longitudinal fasciculus (Hubl et al., 2004; Seok et al., 2007; Shergill et al., 2007). FA in the inferior fronto-occipital fasciculus (Szeszko et al., 2008) and structural co-variance between the frontal and temporal cortex (Modinos et al., 2009) have been shown to correlate with greater severity of hallucinations. Lower FA values in inferior fronto-occipital fasciculus, left superior longitudinal fasciculus and left uncinate fasciculus were significantly associated with higher levels of positive symptoms and with duration of illness (Knochel et al., 2012). Furthermore, in first-episode schizophrenia patients, positive symptoms correlated positively with FA scores in white matter associated with the right frontal lobe, left anterior cingulate gyrus, left superior temporal gyrus, right middle temporal gyrus, right middle cingulate gyrus, and left cuneus (Cheung et al., 2011).

Brain connectivity has also been related to cognitive impairment, functional outcome and other characteristics in schizophrenia patients. Working memory performance has been associated with altered FA in the cingulate fasciculi (Nestor et al., 2010) and left superior longitudinal fasciculus (Karlsgodt et al., 2008), as well as cortical thickness co-variance between the posterior cingulate gyrus and ventral medial prefrontal cortex (Wheeler et al., 2014). Reduced FA in the left inferior longitudinal fasciculus and left inferior fronto-occipital fasciculus has been correlated with reduced processing speed, as well as verbal learning and visual learning abilities (Liu et al., 2013). Additionally, greater declines in intelligence correlated with reduced cingulum white matter FA (Nestor et al., 2013) and FA of several white matter tracts has been related to cognitive performance across a number of domains in people with schizophrenia (Voineskos et al., 2012). Studies have shown that patients with poor outcome compared to good-outcome had more pronounced FA reductions in the posterior corpus callosum and fronto-occipital fasciculus (Mitelman et al., 2007), as well as altered structural co-variance patterns (Mitelman et al., 2005a,b,c). Reduced FA in the inferior longitudinal fasciculus predicted social functioning at follow-up in high-risk subjects (Karlsgodt et al., 2009), and inferior frontal white matter microstructure was associated with impulsivity and aggression in men with schizophrenia (Hoptman et al., 2002). Furthermore, structural covariance relationships differed by sex in patients with schizophrenia (Abbs et al., 2011).

\section{SUMMARY AND CONCLUSIONS}

These studies provide insight into structural connectivity based brain correlates of schizophrenia. Widespread alterations in connectivity are present in the brains of chronic and first episode schizophrenia patients and there is some evidence that patterns of reduced connectivity cut across the different stages of the disorder, including those with an increased risk of developing the illness. Less consistency in first episode, high-risk studies may be because neuroanatomical differences are subtler at the time of illness onset, or because they only appear after a longer time-course in schizophrenia and could possibly be due to treatment. Evidence suggests that differences in the brains of immediate family members are intermediate to patients and control subjects, pointing to a genetic contribution to brain alterations. The diffuse nature of brain abnormalities implies that brain disruption may be related to altered network function. There is a large amount of heterogeneity in structural connectivity findings, some of which may be explained by associations between neuroimaging measures, and symptoms, cognitive performance and outcome.

Many questions about imaging brain connectivity in schizophrenia remain to be answered. Significantly, what are the microscopic neuroanatomical substrates of these changes that are detected with DTI? Reductions in FA may reflect myelin structure, myelin content or axon diameter. These issues may be addressed with advanced imaging or post-mortem studies. Technical advancements in MRI imaging, particularly novel diffusion imaging approaches have the capability to delve further into the underlying architectural changes in the brain. One limitation of current DTI approaches is that each voxel cannot be assumed to contain a single, coherently oriented bundle of white matter axons. Acquisition protocols, such as high angular resolution diffusion-weighted imaging (HARDI) (Tuch et al., 2002) and diffusion spectrum imaging (DSI) (Wedeen et al., 2005, 2008), extract more information from the diffusion-weighted signal and can resolve crossing fibers within voxels. A second limitation is that the DTI model assumes a single pool of diffusing water 


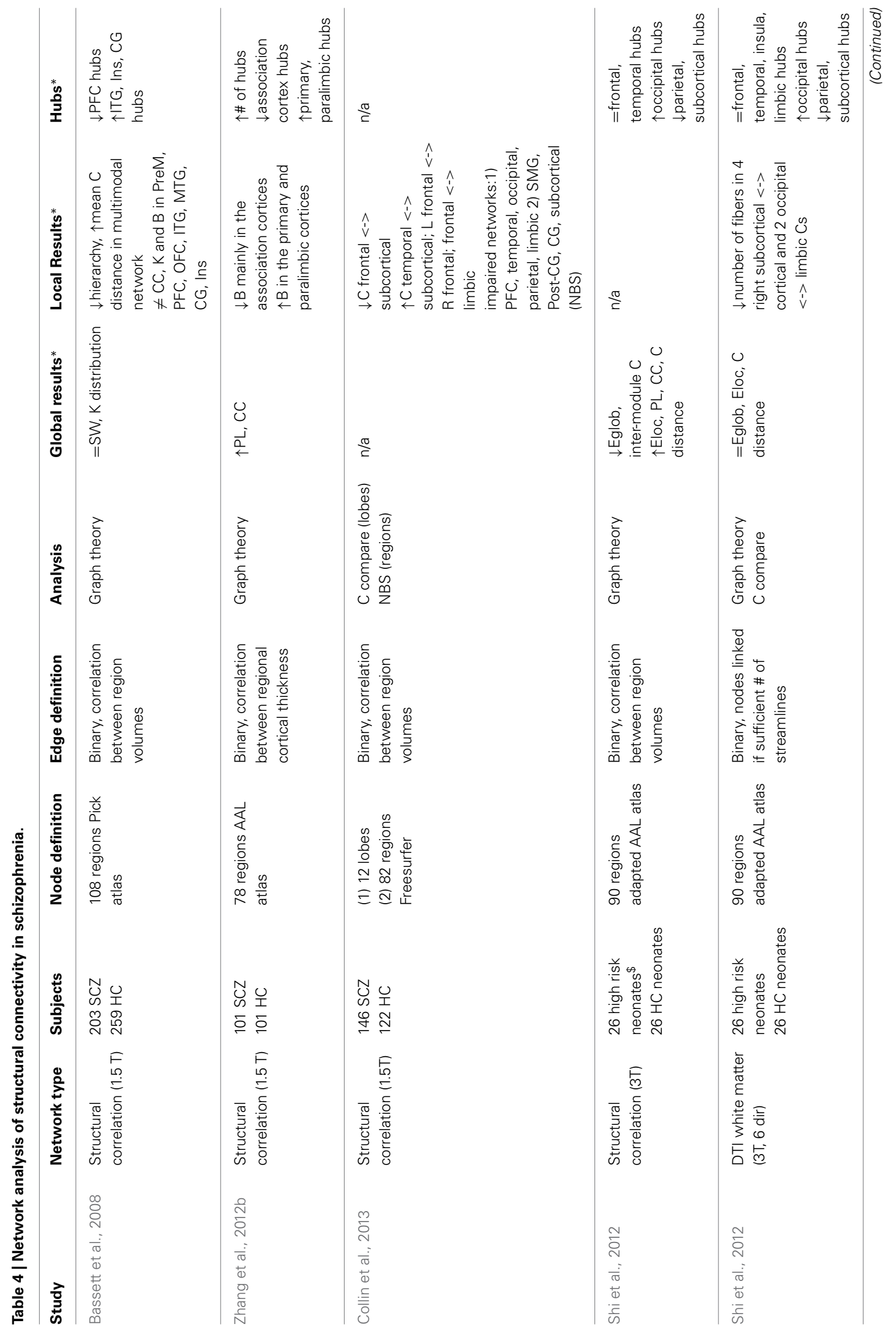




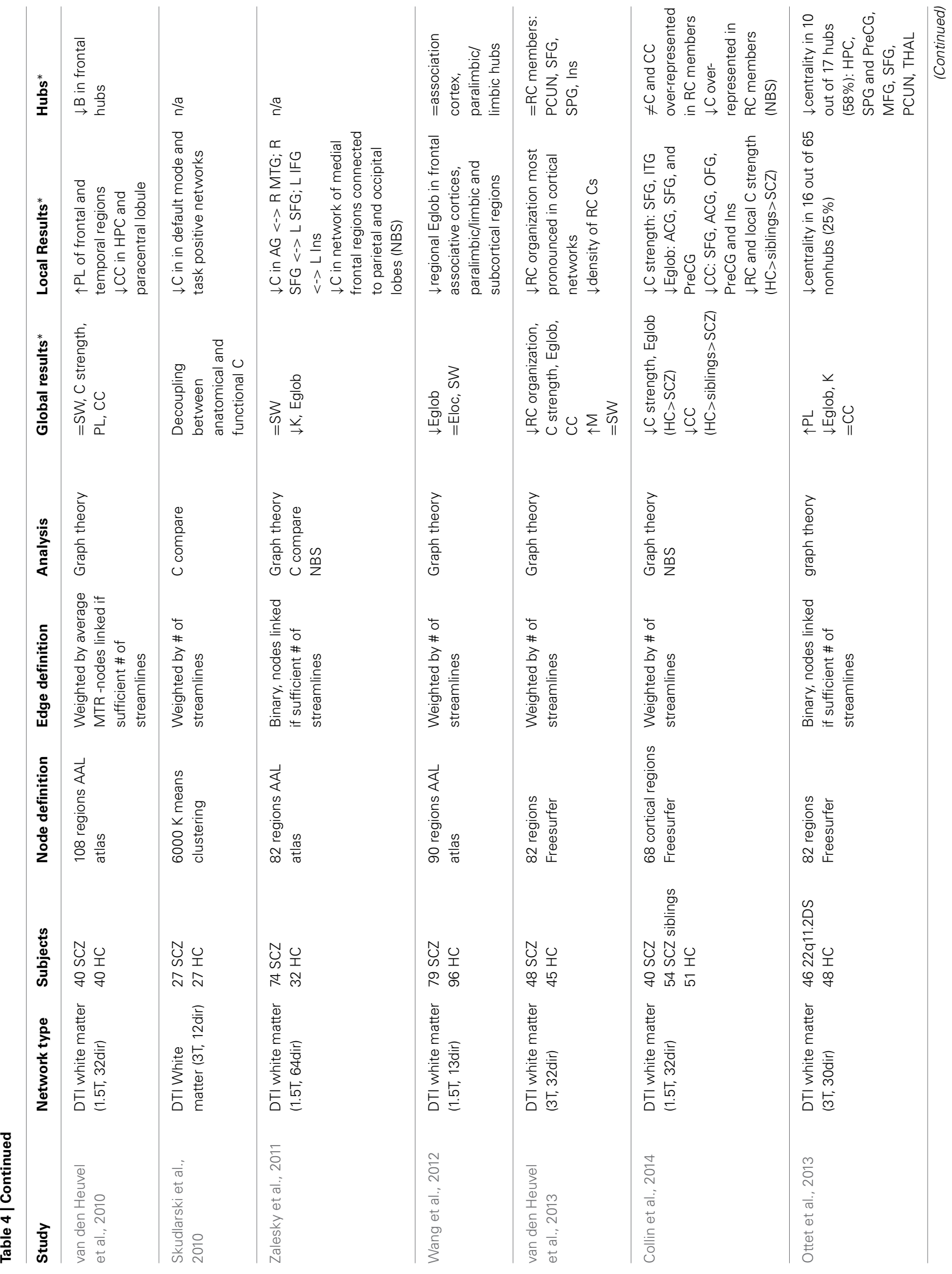




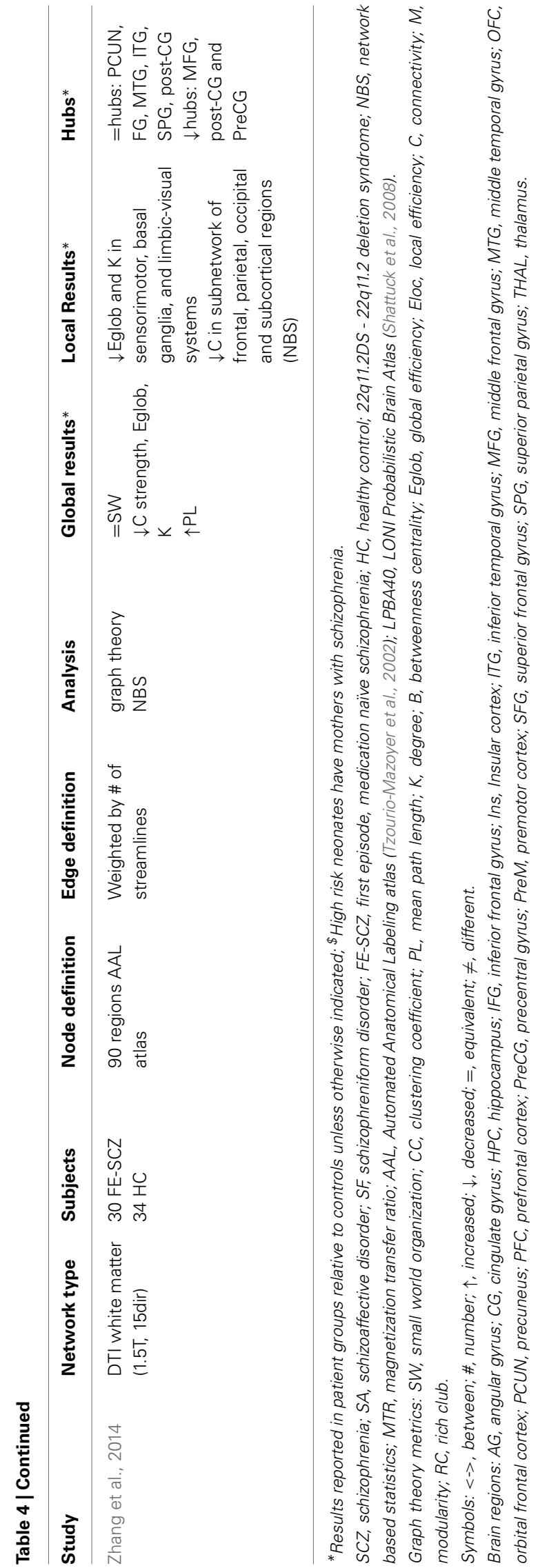

to calculate FA, which does not describe the diffusion decay in white matter. This has been addressed by using a multi-b-value diffusion imaging acquisition protocol that allows for the use of a permeability diffusivity model that estimates the permeability of cellular membranes (Kochunov et al., 2013). Another analytic method separates diffusion properties of brain tissue from surrounding free water permitting computation of the free water volume, which contributes to the architecture surrounding neuronal bundles, and may indicate specific anatomical processes such as neuroinflammation and axonal degeneration (Pasternak et al., 2009). Additionally, neurite orientation dispersion and density imaging (NODDI) allows for the estimation of the microstructural complexity of dendrites and axons by adopting a model-based strategy which relates the signals from diffusion MRI to geometric models of tissue microstructure (Zhang et al., 2012a). Increased sharing of data will allow for increased sample sizes, which will increase the power of statistical analyses and allow for replication of results, a strategy that will greatly benefit the field. With the continued advancement of imaging and analysis techniques, the neural substrates of schizophrenia are certain to be further elucidated. The identification of affected circuits will guide the application of therapeutic interventions to treat this devastating disorder.

\section{ACKNOWLEDGMENTS}

Canadian Institutes of Health Research, Brain and Behavior Research Foundation, CAMH and the CAMH Foundation (thanks to the Kimel family, the Koerner New Scientist Award, and the Paul E. Garfinkel New Investigator Catalyst Award).

\section{REFERENCES}

Abbs, B., Liang, L., Makris, N., Tsuang, M., Seidman, L. J., and Goldstein, J. M. (2011). Covariance modeling of MRI brain volumes in memory circuitry in schizophrenia: sex differences are critical. Neuroimage 56, 1865-1874. doi: 10.1016/j.neuroimage.2011.03.079

Abdul-Rahman, M. F., Qiu, A., and Sim, K. (2011). Regionally specific white matter disruptions of fornix and cingulum in schizophrenia. PLOS ONE 6:e18652. doi: 10.1371/journal.pone.0018652

Alexander-Bloch, A., Giedd, J. N., and Bullmore, E. (2013). Imaging structural covariance between human brain regions. Nat. Rev. Neurosci. 14, 322-336. doi: $10.1038 / \mathrm{nrn} 3465$

Bassett, D. S., Bullmore, E., Verchinski, B. A., Mattay, V. S., Weinberger, D. R., and Meyer-Lindenberg, A. (2008). Hierarchical organization of human cortical networks in health and schizophrenia. J. Neurosci. 28, 9239-9248. doi: 10.1523/JNEUROSCI.1929-08.2008

Bhojraj, T. S., Prasad, K. M., Eack, S. M., Francis, A. N., Montrose, D. M., and Keshavan, M. S. (2010). Do inter-regional gray-matter volumetric correlations reflect altered functional connectivity in high-risk offspring of schizophrenia patients? Schizophr. Res. 118, 62-68. doi: 10.1016/j.schres.2010.01.019

Bloemen, O. J., De Koning, M. B., Schmitz, N., Nieman, D. H., Becker, H. E., De Haan, L., et al. (2009). White-matter markers for psychosis in a prospective ultra-high-risk cohort. Psychol. Med. 40, 1297-1304. doi: 10.1017/S0033291709991711

Boos, H. B., Mandl, R. C., Van Haren, N. E., Cahn, W., Van Baal, G. C., Kahn, R. S., et al. (2012). Tract-based diffusion tensor imaging in patients with schizophrenia and their non-psychotic siblings. Eur. Neuropsychopharmacol. 23, 295-304. doi: 10.1016/j.euroneuro.2012.05.015

Bora, E., Fornito, A., Radua, J., Walterfang, M., Seal, M., Wood, S. J., et al. (2011). Neuroanatomical abnormalities in schizophrenia: a multimodal voxelwise meta-analysis and meta-regression analysis. Schizophr. Res. 127, 46-57. doi: 10.1016/j.schres.2010.12.020

Breier, A., Buchanan, R. W., Elkashef, A., Munson, R. C., Kirkpatrick, B., and Gellad, F. (1992). Brain morphology and schizophrenia. A magnetic resonance 
imaging study of limbic, prefrontal cortex, and caudate structures. Arch. Gen. Psychiatry 49, 921-926.

Buchanan, R. W., Francis, A., Arango, C., Miller, K., Lefkowitz, D. M., McMahon, R. P., et al. (2004). Morphometric assessment of the heteromodal association cortex in schizophrenia. Am. J. Psychiatry 161, 322-331. doi: 10.1176/appi.ajp.161.2.322

Buchsbaum, M. S., Friedman, J., Buchsbaum, B. R., Chu, K. W., Hazlett, E. A., Newmark, R., et al. (2006). Diffusion tensor imaging in schizophrenia. Biol. Psychiatry 60, 1181-1187. doi: 10.1016/j.biopsych.2005.11.028

Bullmore, E. T., and Sporns, O. (2009). Complex brain networks: graph theoretical analysis of structural and functional systems. Nat. Rev. Neurosci. 10, 186-198. doi: $10.1038 / \mathrm{nrn} 2575$

Bullmore, E. T., Woodruff, P. W., Wright, I. C., Rabe-Hesketh, S., Howard, R. J., Shuriquie, N., et al. (1998). Does dysplasia cause anatomical dysconnectivity in schizophrenia? Schizophr. Res. 30, 127-135. doi: 10.1016/S0920-9964(97) 00141-2

Burns, J., Job, D., Bastin, M. E., Whalley, H., MacGillivray, T., Johnstone, E. C., et al. (2003). Structural disconnectivity in schizophrenia: a diffusion tensor magnetic resonance imaging study. Br. J. Psychiatry 182, 439-443. doi: 10.1192/bjp.02.396

Camchong, J., Lim, K. O., Sponheim, S. R., and MacDonald, A. W. (2009). Frontal white matter integrity as an endophenotype for schizophrenia: diffusion tensor imaging in monozygotic twins and patients' nonpsychotic relatives. Front. Hum. Neurosci. 3:35. doi: 10.3389/neuro.09.035.2009

Camchong, J., MacDonald, A. W. 3rd, Bell, C., Mueller, B. A., and Lim, K. O. (2011). Altered functional and anatomical connectivity in schizophrenia. Schizophr. Bull. 37, 640-650. doi: 10.1093/schbul/sbp131

Carletti, F., Woolley, J. B., Bhattacharyya, S., Perez-Iglesias, R., Fusar Poli, P., Valmaggia, L., et al. (2012). Alterations in white matter evident before the onset of psychosis. Schizophr. Bull. 38, 1170-1179. doi: 10.1093/schbul/sbs053

Catani, M., Craig, M. C., Forkel, S. J., Kanaan, R., Picchioni, M., Toulopoulou, T., et al. (2011). Altered integrity of perisylvian language pathways in schizophrenia: relationship to auditory hallucinations. Biol. Psychiatry 70, 1143-1150. doi: 10.1016/j.biopsych.2011.06.013

Chan, W. Y., Yang, G. L., Chia, M. Y., Lau, I. Y., Sitoh, Y. Y., Nowinski, W. L., et al. (2010). White matter abnormalities in first-episode schizophrenia: a combined structural MRI and DTI study. Schizophr. Res. 119, 52-60. doi: 10.1016/j.schres.2009.12.012

Cheung, V., Cheung, C., McAlonan, G. M., Deng, Y., Wong, J. G., Yip, L., et al. (2008). A diffusion tensor imaging study of structural dysconnectivity in never-medicated, first-episode schizophrenia. Psychol. Med. 38, 877-885. doi: 10.1017/S0033291707001808

Cheung, V., Chiu, C. P., Law, C. W., Cheung, C., Hui, C. L., Chan, K. K., et al. (2011). Positive symptoms and white matter microstructure in nevermedicated first episode schizophrenia. Psychol. Med. 41, 1709-1719. doi: 10.1017/S003329171000156X

Choi, H., Kubicki, M., Whitford, T. J., Alvarado, J. L., Terry, D. P., Niznikiewicz, M., et al. (2011). Diffusion tensor imaging of anterior commissural fibers in patients with schizophrenia. Schizophr. Res. 130, 78-85. doi: 10.1016/j.schres.2011.04.016

Clark, K. A., Nuechterlein, K. H., Asarnow, R. F., Hamilton, L. S., Phillips, O. R., Hageman, N. S., et al. (2011). Mean diffusivity and fractional anisotropy as indicators of disease and genetic liability to schizophrenia. J. Psychiatr. Res. 45, 980-988. doi: 10.1016/j.jpsychires.2011.01.006

Clark, K., Narr, K. L., O’Neill, J., Levitt, J., Siddarth, P., Phillips, O., et al. (2012). White matter integrity, language, and childhood onset schizophrenia. Schizophr. Res. 138, 150-156. doi: 10.1016/j.schres.2012.02.016

Clemm von Hohenberg, C., Pasternak, O., Kubicki, M., Ballinger, T., Vu, M. A., Swisher, T., et al. (2014). White matter microstructure in individuals at clinical high risk of psychosis: a whole-brain diffusion tensor imaging study. Schizophr. Bull. 40, 895-903. doi: 10.1093/schbul/sbt079

Collin, G., de Reus, M. A., Cahn, W., Hulshoff Pol, H. E., Kahn, R. S., and van den Heuvel, M. P. (2013). Disturbed grey matter coupling in schizophrenia. Eur. Neuropsychopharmacol. 23, 46-54. doi: 10.1016/j.euroneuro.2012.09.001

Collin, G., Kahn, R. S., de Reus, M. A., Cahn, W., and van den Heuvel, M. P. (2014). Impaired rich club connectivity in unaffected siblings of schizophrenia patients. Schizophr. Bull. 40, 438-448. doi: 10.1093/schbul/sbt162

Craddock, R. C., Jbabdi, S., Yan, C. G., Vogelstein, J. T., Castellanos, F. X., Di Martino, A., et al. (2013). Imaging human connectomes at the macroscale. Nat. Methods 10, 524-539. doi: 10.1038/nmeth.2482
Csernansky, J. G., Schindler, M. K., Splinter, N. R., Wang, L., Gado, M., Selemon, L. D., et al. (2004). Abnormalities of thalamic volume and shape in schizophrenia. Am. J. Psychiatry 161, 896-902. doi: 10.1176/appi.ajp.161.5.896

Cui, L., Chen, Z., Deng, W., Huang, X., Li, M., Ma, X., et al. (2011). Assessment of white matter abnormalities in paranoid schizophrenia and bipolar mania patients. Psychiatry Res. 194, 347-353. doi: 10.1016/j.pscychresns.2011.03.010

Cullen, K. R., Wallace, S., Magnotta, V. A., Bockholt, J., Ehrlich, S., Gollub, R. L., et al. (2012). Cigarette smoking and white matter microstructure in schizophrenia. Psychiatry Res. 201, 152-158. doi: 10.1016/j.pscychresns.2011.08.010

Dekker, N., Schmitz, N., Peters, B. D., Van Amelsvoort, T. A., Linszen, D. H., and De Haan, L. (2010). Cannabis use and callosal white matter structure and integrity in recent-onset schizophrenia. Psychiatry Res. 181, 51-56. doi: 10.1016/j.pscychresns.2009.06.003

de Weijer, A. D., Mandl, R. C., Diederen, K. M., Neggers, S. F., Kahn, R. S., Hulshoff Pol, H. E., et al. (2011). Microstructural alterations of the arcuate fasciculus in schizophrenia patients with frequent auditory verbal hallucinations. Schizophr. Res. 130, 68-77. doi: 10.1016/j.schres.2011.05.010

Ellison-Wright, I., and Bullmore, E. (2009). Meta-analysis of diffusion tensor imaging studies in schizophrenia. Schizophr. Res. 108, 3-10. doi: 10.1016/j.schres.2008.11.021

Federspiel, A., Begre, S., Kiefer, C., Schroth, G., Strik, W. K., and Dierks, T. (2006). Alterations of white matter connectivity in first episode schizophrenia. Neurobiol. Dis. 22, 702-709. doi: 10.1016/j.nbd.2006.01.015

Filippi, M., Canu, E., Gasparotti, R., Agosta, F., Valsecchi, P., Lodoli, G., et al. (2014). Patterns of brain structural changes in first-contact, antipsychotic drugnaive patients with schizophrenia. AJNR Am. J. Neuroradiol. 35, 30-37. doi: 10.3174/ajnr.A3583

Fitzsimmons, J., Kubicki, M., and Shenton, M. E. (2013). Review of functional and anatomical brain connectivity findings in schizophrenia. Curr. Opin. Psychiatry 26, 172-187. doi: 10.1097/YCO.0b013e32835d9e6a

Foong, J., Maier, M., Clark, C. A., Barker, G. J., Miller, D. H., and Ron, M. A. (2000). Neuropathological abnormalities of the corpus callosum in schizophrenia: a diffusion tensor imaging study. J. Neurol. Neurosurg. Psychiatr. 68, 242-244. doi: 10.1136/jnnp.68.2.242

Foong, J., Symms, M. R., Barker, G. J., Maier, M., Miller, D. H., and Ron, M. A. (2002). Investigating regional white matter in schizophrenia using diffusion tensor imaging. Neuroreport 13, 333-336. doi: 10.1097/00001756-20020304000017

Friedman, J. I., Tang, C., Carpenter, D., Buchsbaum, M., Schmeidler, J., Flanagan, L., et al. (2008). Diffusion tensor imaging findings in first-episode and chronic schizophrenia patients. Am. J. Psychiatry 165, 1024-1032. doi: 10.1176/appi.ajp.2008.07101640

Friston, K. J., and Frith, C. D. (1995). Schizophrenia: a disconnection syndrome? Clin. Neurosci. 3, 89-97.

Fujino, J., Takahashi, H., Miyata, J., Sugihara, G., Kubota, M., Sasamoto, A., et al. (2014). Impaired empathic abilities and reduced white matter integrity in schizophrenia. Prog. Neuropsychopharmacol. Biol. Psychiatry 48, 117-123. doi: 10.1016/j.pnpbp.2013.09.018

Fujiwara, H., Namiki, C., Hirao, K., Miyata, J., Shimizu, M., Fukuyama, H., et al. (2007). Anterior and posterior cingulum abnormalities and their association with psychopathology in schizophrenia: a diffusion tensor imaging study. Schizophr. Res. 95, 215-222. doi: 10.1016/j.schres.2007.05.044

Gasparotti, R., Valsecchi, P., Carletti, F., Galluzzo, A., Liserre, R., Cesana, B., et al. (2009). Reduced fractional anisotropy of corpus callosum in firstcontact, antipsychotic drug-naive patients with schizophrenia. Schizophr. Res. 108, 41-48. doi: 10.1016/j.schres.2008.11.015

Gong, G., He, Y., Chen, Z. J., and Evans, A. C. (2012). Convergence and divergence of thickness correlations with diffusion connections across the human cerebral cortex. Neuroimage 59, 1239-1248. doi: 10.1016/j.neuroimage.2011.08.017

Guo, W., Liu, F., Liu, Z., Gao, K., Xiao, C., Chen, H., et al. (2012). Right lateralized white matter abnormalities in first-episode, drug-naive paranoid schizophrenia. Neurosci. Lett. 531, 5-9. doi: 10.1016/j.neulet.2012.09.033

Hao, Y., Liu, Z., Jiang, T., Gong, G., Liu, H., Tan, L., et al. (2006). White matter integrity of the whole brain is disrupted in first-episode schizophrenia. Neuroreport 17, 23-26. doi: 10.1097/01.wnr.0000195664.15090.46

Hao, Y., Yan, Q., Liu, H., Xu, L., Xue, Z., Song, X., et al. (2009). Schizophrenia patients and their healthy siblings share disruption of white matter integrity in the left prefrontal cortex and the hippocampus but not the anterior cingulate cortex. Schizophr. Res. 114, 128-135. doi: 10.1016/j.schres.2009.07.001 
Henze, R., Brunner, R., Thiemann, U., Parzer, P., Klein, J., Resch, F., et al. (2012). White matter alterations in the corpus callosum of adolescents with first-admission schizophrenia. Neurosci. Lett. 513, 178-182. doi: 10.1016/j.neulet.2012.02.032

Ho, B. C., Andreasen, N. C., Ziebell, S., Pierson, R., and Magnotta, V. (2011). Longterm antipsychotic treatment and brain volumes: a longitudinal study of firstepisode schizophrenia. Arch. Gen. Psychiatry 68, 128-137. doi: 10.1001/archgenpsychiatry.2010.199

Hoptman, M. J., Nierenberg, J., Bertisch, H. C., Catalano, D., Ardekani, B. A., Branch, C. A., et al. (2008). A DTI study of white matter microstructure in individuals at high genetic risk for schizophrenia. Schizophr. Res. 106, 115-124. doi: 10.1016/j.schres.2008.07.023

Hoptman, M. J., Volavka, J., Johnson, G., Weiss, E., Bilder, R. M., and Lim, K. O. (2002). Frontal white matter microstructure, aggression, and impulsivity in men with schizophrenia: a preliminary study. Biol. Psychiatry 52, 9-14. doi: 10.1016/S0006-3223(02)01311-2

Hubl, D., Koenig, T., Strik, W., Federspiel, A., Kreis, R., Boesch, C., et al. (2004). Pathways that make voices: white matter changes in auditory hallucinations. Arch. Gen. Psychiatry 61, 658-668. doi: 10.1001/archpsyc.61.7.658

Kanaan, R. A., Kim, J. S., Kaufmann, W. E., Pearlson, G. D., Barker, G. J., and McGuire, P. K. (2005). Diffusion tensor imaging in schizophrenia. Biol. Psychiatry 58, 921-929. doi: 10.1016/j.biopsych.2005.05.015

Karlsgodt, K. H., Niendam, T. A., Bearden, C. E., and Cannon, T. D. (2009). White matter integrity and prediction of social and role functioning in subjects at ultra-high risk for psychosis. Biol. Psychiatry 66, 562-569. doi: 10.1016/j.biopsych.2009.03.013

Karlsgodt, K. H., Van Erp, T. G., Poldrack, R. A., Bearden, C. E., Nuechterlein, K. H., and Cannon, T. D. (2008). Diffusion tensor imaging of the superior longitudinal fasciculus and working memory in recent-onset schizophrenia. Biol. Psychiatry 63, 512-518. doi: 10.1016/j.biopsych.2007.06.017

Kawashima, T., Nakamura, M., Bouix, S., Kubicki, M., Salisbury, D. F., Westin, C. F., et al. (2009). Uncinate fasciculus abnormalities in recent onset schizophrenia and affective psychosis: a diffusion tensor imaging study. Schizophr. Res. 110 119-126. doi: 10.1016/j.schres.2009.01.014

Kim, S. H., Lee, J. M., Kim, H. P., Jang, D. P., Shin, Y. W., Ha, T. H., et al. (2005). Asymmetry analysis of deformable hippocampal model using the principal component in schizophrenia. Hum. Brain Mapp. 25, 361-369. doi: 10.1002/hbm.20106

Kitis, O., Eker, M. C., Zengin, B., Akyilmaz, D. A., Yalvac, D., Ozdemir, H. I., et al. (2011). The disrupted connection between cerebral hemispheres in schizophrenia patients: a diffusion tensor imaging study. Turk Psikiyatri Derg. 22, 213-221.

Kitis, O., Ozalay, O., Zengin, E. B., Haznedaroglu, D., Eker, M. C., Yalvac, D. et al. (2012). Reduced left uncinate fasciculus fractional anisotropy in deficit schizophrenia but not in non-deficit schizophrenia. Psychiatry Clin. Neurosci. 66, 34-43. doi: 10.1111/j.1440-1819.2011.02293.x

Knochel, C., O’Dwyer, L., Alves, G., Reinke, B., Magerkurth, J., Rotarska-Jagiela, A., et al. (2012). Association between white matter fiber integrity and subclinical psychotic symptoms in schizophrenia patients and unaffected relatives. Schizophr. Res. 140, 129-135. doi: 10.1016/j.schres.2012.06.001

Kochunov, P., Chiappelli, J., and Hong, L. E. (2013). Permeability-diffusivity modeling vs. fractional anisotropy on white matter integrity assessment and application in schizophrenia. Neuroimage Clin 3, 18-26. doi: 10.1016/j.nicl.2013. 06.019

Kochunov, P., and Hong, L. E. (2014). Neurodevelopmental and neurodegenerative models of schizophrenia: white matter at the center stage. Schizophr. Bull. 40, 721-728. doi: 10.1093/schbul/sbu070

Kong, X., Ouyang, X., Tao, H., Liu, H., Li, L., Zhao, J., et al. (2011). Complementary diffusion tensor imaging study of the corpus callosum in patients with firstepisode and chronic schizophrenia. J. Psychiatry Neurosci. 36, 120-125. doi: 10.1503/jpn.100041

Kubicki, M., Park, H., Westin, C. F., Nestor, P. G., Mulkern, R. V., Maier, S. E., et al. (2005). DTI and MTR abnormalities in schizophrenia: analysis of white matter integrity. Neuroimage 26, 1109-1118. doi: 10.1016/j.neuroimage.2005 03.026

Kubicki, M., Styner, M., Bouix, S., Gerig, G., Markant, D., Smith, K., et al (2008). Reduced interhemispheric connectivity in schizophrenia-tractography based segmentation of the corpus callosum. Schizophr. Res. 106, 125-131. doi: 10.1016/j.schres.2008.08.027
Kubicki, M., Westin, C. F., Nestor, P. G., Wible, C. G., Frumin, M., Maier, S. E., et al. (2003). Cingulate fasciculus integrity disruption in schizophrenia: a magnetic resonance diffusion tensor imaging study. Biol. Psychiatry 54, 1171-1180. doi: 10.1016/S0006-3223(03)00419-0

Kunimatsu, N., Aoki, S., Kunimatsu, A., Abe, O., Yamada, H., Masutani, Y., et al. (2012). Tract-specific analysis of white matter integrity disruption in schizophrenia. Psychiatry Res. 201, 136-143. doi: 10.1016/j.pscychresns.2011.07.010

Lawrie, S. M., McIntosh, A. M., Hall, J., Owens, D. G., and Johnstone, E. C. (2008). Brain structure and function changes during the development of schizophrenia: the evidence from studies of subjects at increased genetic risk. Schizophr. Bull. 34, 330-340. doi: 10.1093/schbul/sbm158

Lee, D. Y., Smith, G. N., Su, W., Honer, W. G., Macewan, G. W., Lapointe, J. S., et al (2012). White matter tract abnormalities in first-episode psychosis. Schizophr. Res. 141, 29-34. doi: 10.1016/j.schres.2012.06.042

Lee, S. H., Kubicki, M., Asami, T., Seidman, L. J., Goldstein, J. M., MesholamGately, R. I., et al. (2013). Extensive white matter abnormalities in patients with first-episode schizophrenia: a Diffusion Tensor Iimaging (DTI) study. Schizophr. Res. 143, 231-238. doi: 10.1016/j.schres.2012.11.029

Lett, T. A., Chakavarty, M. M., Felsky, D., Brandl, E. J., Tiwari, A. K., Goncalves, V. F., et al. (2013). The genome-wide supported microRNA-137 variant predicts phenotypic heterogeneity within schizophrenia. Mol. Psychiatry 18, 443-450. doi: $10.1038 / \mathrm{mp} .2013 .17$

Levitt, J. J., Alvarado, J. L., Nestor, P. G., Rosow, L., Pelavin, P. E., McCarley, R. W. et al. (2012). Fractional anisotropy and radial diffusivity: diffusion measures of white matter abnormalities in the anterior limb of the internal capsule in schizophrenia. Schizophr. Res. 136, 55-62. doi: 10.1016/j.schres.2011.09.009

Lim, K. O., Hedehus, M., Moseley, M., De Crespigny, A., Sullivan, E. V., and Pfefferbaum, A. (1999). Compromised white matter tract integrity in schizophrenia inferred from diffusion tensor imaging. Arch. Gen. Psychiatry 56, 367-374.

Liu, X., Lai, Y., Wang, X., Hao, C., Chen, L., Zhou, Z., et al. (2013). Reduced white matter integrity and cognitive deficit in never-medicated chronic schizophrenia: a diffusion tensor study using TBSS. Behav. Brain Res. 252, 157-163. doi: 10.1016/j.bbr.2013.05.061

Luck, D., Buchy, L., Czechowska, Y., Bodnar, M., Pike, G. B., Campbell, J. S., et al. (2011). Fronto-temporal disconnectivity and clinical short-term outcome in first episode psychosis: a DTI-tractography study. J. Psychiatr. Res. 45, 369-377. doi: 10.1016/j.jpsychires.2010.07.007

Mandl, R. C., Rais, M., Van Baal, G. C., Van Haren, N. E., Cahn, W., Kahn, R. S., et al. (2012). Altered white matter connectivity in never-medicated patients with schizophrenia. Hum. Brain Mapp. 34, 2353-2365. doi: 10.1002/hbm.22075

Manoach, D. S., Ketwaroo, G. A., Polli, F. E., Thakkar, K. N., Barton, J. J., Goff, D. C., et al. (2007). Reduced microstructural integrity of the white matter underlying anterior cingulate cortex is associated with increased saccadic latency in schizophrenia. Neuroimage 37, 599-610. doi: 10.1016/j.neuroimage.2007.04.062

Melonakos, E. D., Shenton, M. E., Rathi, Y., Terry, D. P., Bouix, S., and Kubicki, M. (2011). Voxel-based morphometry (VBM) studies in schizophrenia-can white matter changes be reliably detected with VBM? Psychiatry Res. 193, 65-70. doi: 10.1016/j.pscychresns.2011.01.009

Mendelsohn, A., Strous, R. D., Bleich, M., Assaf, Y., and Hendler, T. (2006) Regional axonal abnormalities in first episode schizophrenia: preliminary evidence based on high b-value diffusion-weighted imaging. Psychiatry Res. 146 223-229. doi: 10.1016/j.pscychresns.2005.12.010

Minami, T., Nobuhara, K., Okugawa, G., Takase, K., Yoshida, T., Sawada, S., et al. (2003). Diffusion tensor magnetic resonance imaging of disruption of regional white matter in schizophrenia. Neuropsychobiology 47, 141-145. doi: 10.1159/000070583

Mitelman, S. A., Brickman, A. M., Shihabuddin, L., Newmark, R., Chu, K. W., and Buchsbaum, M. S. (2005a). Correlations between MRI-assessed volumes of the thalamus and cortical Brodmann's areas in schizophrenia. Schizophr. Res. 75, 265-281. doi: 10.1016/j.schres.2004.10.014

Mitelman, S. A., Buchsbaum, M. S., Brickman, A. M., and Shihabuddin, L. (2005b) Cortical intercorrelations of frontal area volumes in schizophrenia. Neuroimage 27, 753-770. doi: 10.1016/j.neuroimage.2005.05.024

Mitelman, S. A., Byne, W., Kemether, E. M., Hazlett, E. A., and Buchsbaum, M. S. (2006). Correlations between volumes of the pulvinar, centromedian, and mediodorsal nuclei and cortical Brodmann's areas in schizophrenia. Neurosci. Lett. 392, 16-21. doi: 10.1016/j.neulet.2005.08.056 
Mitelman, S. A., Shihabuddin, L., Brickman, A. M., and Buchsbaum, M. S. (2005c). Cortical intercorrelations of temporal area volumes in schizophrenia. Schizophr. Res. 76, 207-229. doi: 10.1016/j.schres.2005.01.010

Mitelman, S. A., Torosjan, Y., Newmark, R. E., Schneiderman, J. S., Chu, K. W., Brickman, A. M., et al. (2007). Internal capsule, corpus callosum and long associative fibers in good and poor outcome schizophrenia: a diffusion tensor imaging survey. Schizophr. Res. 92, 211-224. doi: 10.1016/j.schres.2006.12.029

Modinos, G., Vercammen, A., Mechelli, A., Knegtering, H., McGuire, P. K., and Aleman, A. (2009). Structural covariance in the hallucinating brain: a voxelbased morphometry study. J. Psychiatry Neurosci. 34, 465-469.

Mori, T., Ohnishi, T., Hashimoto, R., Nemoto, K., Moriguchi, Y., Noguchi, H., et al. (2007). Progressive changes of white matter integrity in schizophrenia revealed by diffusion tensor imaging. Psychiatry Res. 154, 133-145. doi: 10.1016/j.pscychresns.2006.09.004

Moriya, J., Kakeda, S., Abe, O., Goto, N., Yoshimura, R., Hori, H., et al. (2010). Gray and white matter volumetric and diffusion tensor imaging (DTI) analyses in the early stage of first-episode schizophrenia. Schizophr. Res. 116, 196-203. doi: 10.1016/j.schres.2009.10.002

Munoz Maniega, S., Lymer, G. K., Bastin, M. E., Marjoram, D., Job, D. E., Moorhead, T. W., et al. (2008). A diffusion tensor MRI study of white matter integrity in subjects at high genetic risk of schizophrenia. Schizophr. Res. 106, 132-139. doi: 10.1016/j.schres.2008.09.016

Nakamura, K., Kawasaki, Y., Takahashi, T., Furuichi, A., Noguchi, K., Seto, H., et al. (2012). Reduced white matter fractional anisotropy and clinical symptoms in schizophrenia: a voxel-based diffusion tensor imaging study. Psychiatry Res. 202, 233-238. doi: 10.1016/j.pscychresns.2011.09.006

Nazeri, A., Chakravarty, M. M., Felsky, D., Lobaugh, N. J., Rajji, T. K., Mulsant, B. H., et al. (2013). Alterations of superficial white matter in schizophrenia and relationship to cognitive performance. Neuropsychopharmacology 38, 1954-1962. doi: 10.1038/npp.2013.93

Nestor, P. G., Kubicki, M., Nakamura, M., Niznikiewicz, M., Levitt, J. J., Shenton, M. E., et al. (2013). Neuropsychological variability, symptoms, and brain imaging in chronic schizophrenia. Brain Imaging Behav. 7, 68-76. doi: 10.1007/s11682-012-9193-0

Nestor, P. G., Kubicki, M., Nakamura, M., Niznikiewicz, M., McCarley, R. W., and Shenton, M. E. (2010). Comparing prefrontal gray and white matter contributions to intelligence and decision making in schizophrenia and healthy controls. Neuropsychology 24, 121-129. doi: 10.1037/a0016981

Niznikiewicz, M., Donnino, R., McCarley, R. W., Nestor, P. G., Iosifescu, D. V., O'Donnell, B., et al. (2000). Abnormal angular gyrus asymmetry in schizophrenia. Am. J. Psychiatry 157, 428-437. doi: 10.1176/appi.ajp.157.3.428

Oh, J. S., Kubicki, M., Rosenberger, G., Bouix, S., Levitt, J. J., McCarley, R. W., et al. (2009). Thalamo-frontal white matter alterations in chronic schizophrenia: a quantitative diffusion tractography study. Hum. Brain Mapp. 30, 3812-3825. doi: $10.1002 / \mathrm{hbm} .20809$

Okugawa, G., Nobuhara, K., Minami, T., Tamagaki, C., Takase, K., Sugimoto, T., et al. (2004). Subtle disruption of the middle cerebellar peduncles in patients with schizophrenia. Neuropsychobiology 50, 119-123. doi: $10.1159 / 00007910179101$

Ottet, M. C., Schaer, M., Debbane, M., Cammoun, L., Thiran, J. P., and Eliez, S. (2013). Graph theory reveals dysconnected hubs in 22q11DS and altered nodal efficiency in patients with hallucinations. Front. Hum. Neurosci. 7:402. doi: 10.3389/fnhum.2013.00402

Pantelis, C., Velakoulis, D., Wood, S. J., Yucel, M., Yung, A. R., Phillips, L. J., et al. (2007). Neuroimaging and emerging psychotic disorders: the Melbourne ultra-high risk studies. Int. Rev. Psychiatry 19, 371-381. doi: 10.1080/09540260701512079

Pasternak, O., Sochen, N., Gur, Y., Intrator, N., and Assaf, Y. (2009). Free water elimination and mapping from diffusion MRI. Magn. Reson. Med. 62, 717-730. doi: $10.1002 / \mathrm{mrm} .22055$

Pasternak, O., Westin, C. F., Bouix, S., Seidman, L. J., Goldstein, J. M., Woo, T. U., et al. (2012). Excessive extracellular volume reveals a neurodegenerative pattern in schizophrenia onset. J. Neurosci. 32, 17365-17372. doi: 10.1523/JNEUROSCI.2904-12.2012

Perez-Iglesias, R., Tordesillas-Gutierrez, D., Barker, G. J., McGuire, P. K., RoizSantianez, R., Mata, I., et al. (2010). White matter defects in first episode psychosis patients: a voxelwise analysis of diffusion tensor imaging. Neuroimage 49, 199-204. doi: 10.1016/j.neuroimage.2009.07.016
Peters, B. D., De Haan, L., Dekker, N., Blaas, J., Becker, H. E., Dingemans, P. M., et al. (2008). White matter fibertracking in first-episode schizophrenia, schizoaffective patients and subjects at ultra-high risk of psychosis. Neuropsychobiology 58, 19-28. doi: 10.1159/000154476

Peters, B. D., Dingemans, P. M., Dekker, N., Blaas, J., Akkerman, E., Van Amelsvoort, T. A., et al. (2010). White matter connectivity and psychosis in ultra-high-risk subjects: a diffusion tensor fiber tracking study. Psychiatry Res. 181, 44-50. doi: 10.1016/j.pscychresns.2009.10.008

Peters, B. D., Schmitz, N., Dingemans, P. M., Van Amelsvoort, T. A., Linszen, D. H., De Haan, L., et al. (2009). Preliminary evidence for reduced frontal white matter integrity in subjects at ultra-high-risk for psychosis. Schizophr. Res. 111, 192-193. doi: 10.1016/j.schres.2009.03.018

Peters, B. D., Szeszko, P. R., Radua, J., Ikuta, T., Gruner, P., Derosse, P., et al. (2012). White matter development in adolescence: diffusion tensor imaging and metaanalytic results. Schizophr. Bull. 38, 1308-1317. doi: 10.1093/schbul/sbs054

Pettersson-Yeo, W., Allen, P., Benetti, S., McGuire, P., and Mechelli, A. (2011), Dysconnectivity in schizophrenia: where are we now? Neurosci. Biobehav. Rev. 35, 1110-1124. doi: 10.1016/j.neubiorev.2010.11.004

Phillips, O. R., Nuechterlein, K. H., Asarnow, R. F., Clark, K. A., Cabeen, R., Yang, Y., et al. (2011). Mapping corticocortical structural integrity in schizophrenia and effects of genetic liability. Biol. Psychiatry 70, 680-689. doi: 10.1016/j.biopsych.2011.03.039

Phillips, O. R., Nuechterlein, K. H., Clark, K. A., Hamilton, L. S., Asarnow, R. F., Hageman, N. S., et al. (2009). Fiber tractography reveals disruption of temporal lobe white matter tracts in schizophrenia. Schizophr. Res. 107, 30-38. doi: 10.1016/j.schres.2008.10.019

Portas, C. M., Goldstein, J. M., Shenton, M. E., Hokama, H. H., Wible, C. G., Fischer, I., et al. (1998). Volumetric evaluation of the thalamus in schizophrenic male patients using magnetic resonance imaging. Biol. Psychiatry 43, 649-659.

Price, G., Bagary, M. S., Cercignani, M., Altmann, D. R., and Ron, M. A. (2005). The corpus callosum in first episode schizophrenia: a diffusion tensor imaging study. J. Neurol. Neurosurg. Psychiatr. 76, 585-587. doi: 10.1136/jnnp.2004.042952

Price, G., Cercignani, M., Parker, G. J., Altmann, D. R., Barnes, T. R., Barker, G. J., et al. (2007). Abnormal brain connectivity in first-episode psychosis: a diffusion MRI tractography study of the corpus callosum. Neuroimage 35, 458-466. doi: 10.1016/j.neuroimage.2006.12.019

Price, G., Cercignani, M., Parker, G. J., Altmann, D. R., Barnes, T. R., Barker, G. J., et al. (2008). White matter tracts in first-episode psychosis: a DTI tractography study of the uncinate fasciculus. Neuroimage 39, 949-955. doi: 10.1016/j.neuroimage.2007.09.012

Qiu, A., Zhong, J., Graham, S., Chia, M. Y., and Sim, K. (2009). Combined analyses of thalamic volume, shape and white matter integrity in first-episode schizophrenia. Neuroimage 47, 1163-1171. doi: 10.1016/j.neuroimage.2009.04.027

Rathi, Y., Kubicki, M., Bouix, S., Westin, C. F., Goldstein, J., Seidman, L., et al. (2011). Statistical analysis of fiber bundles using multi-tensor tractography: application to first-episode schizophrenia. Magn. Reson. Imaging 29, 507-515. doi: 10.1016/j.mri.2010.10.005

Ratnanather, J. T., Poynton, C. B., Pisano, D. V., Crocker, B., Postell, E., Cebron, S. et al. (2013). Morphometry of superior temporal gyrus and planum temporale in schizophrenia and psychotic bipolar disorder. Schizophr. Res. 150, 476-483. doi: 10.1016/j.schres.2013.08.014

Reading, S. A., Oishi, K., Redgrave, G. W., McEntee, J., Shanahan, M., Yoritomo, N., et al. (2011). Diffuse abnormality of low to moderately organized white matter in schizophrenia. Brain Connect. 1, 511-519. doi: 10.1089/brain.2011.0041

Roalf, D. R., Ruparel, K., Verma, R., Elliott, M. A., Gur, R. E., and Gur, R. C. (2013). White matter organization and neurocognitive performance variability in schizophrenia. Schizophr. Res. 143, 172-178. doi: 10.1016/j.schres.2012.10.014

Rosenberger, G., Nestor, P. G., Oh, J. S., Levitt, J. J., Kindleman, G., Bouix, S., et al. (2012). Anterior limb of the internal capsule in schizophrenia: a diffusion tensor tractography study. Brain Imaging Behav. 6, 417-425. doi: 10.1007/s11682-0129152-9

Rotarska-Jagiela, A., Oertel-Knoechel, V., Demartino, F., Van De Ven, V., Formisano, E., Roebroeck, A., et al. (2009). Anatomical brain connectivity and positive symptoms of schizophrenia: a diffusion tensor imaging study. Psychiatry Res. 174, 9-16. doi: 10.1016/j.pscychresns.2009.03.002

Rotarska-Jagiela, A., Schonmeyer, R., Oertel, V., Haenschel, C., Vogeley, K., and Linden, D. E. (2008). The corpus callosum in schizophrenia-volume and 
connectivity changes affect specific regions. Neuroimage 39, 1522-1532. doi: 10.1016/j.neuroimage.2007.10.063

Rowland, L. M., Spieker, E. A., Francis, A., Barker, P. B., Carpenter, W. T., and Buchanan, R. W. (2009). White matter alterations in deficit schizophrenia. Neuropsychopharmacology 34, 1514-1522. doi: 10.1038/npp.2008.207

Rubinov, M., and Bullmore, E. (2013). Schizophrenia and abnormal brain network hubs. Dialogues Clin. Neurosci. 15, 339-349.

Ruef, A., Curtis, L., Moy, G., Bessero, S., Badan Ba, M., Lazeyras, F., et al. (2012). Magnetic resonance imaging correlates of first-episode psychosis in young adult male patients: combined analysis of grey and white matter. J. Psychiatry Neurosci. 37, 305-312. doi: 10.1503/jpn.110057

Scheel, M., Prokscha, T., Bayerl, M., Gallinat, J., and Montag, C. (2012). Myelination deficits in schizophrenia: evidence from diffusion tensor imaging. Brain Struct. Funct. 218, 151-156. doi: 10.1007/s00429-012-0389-2

Schneiderman, J. S., Hazlett, E. A., Chu, K. W., Zhang, J., Goodman, C. R., Newmark, R. E., et al. (2011). Brodmann area analysis of white matter anisotropy and age in schizophrenia. Schizophr. Res. 130, 57-67. doi: 10.1016/j.schres.2011.04.027

Seal, M. L., Yucel, M., Fornito, A., Wood, S. J., Harrison, B. J., Walterfang, M., et al. (2008). Abnormal white matter microstructure in schizophrenia: a voxelwise analysis of axial and radial diffusivity. Schizophr. Res. 101, 106-110. doi: 10.1016/j.schres.2007.12.489

Segal, D., Haznedar, M. M., Hazlett, E. A., Entis, J. J., Newmark, R. E., Torosjan, Y., et al. (2010). Diffusion tensor anisotropy in the cingulate gyrus in schizophrenia. Neuroimage 50, 357-365. doi: 10.1016/j.neuroimage.2009.12.071

Seok, J. H., Park, H. J., Chun, J. W., Lee, S. K., Cho, H. S., Kwon, J. S., et al. (2007). White matter abnormalities associated with auditory hallucinations in schizophrenia: a combined study of voxel-based analyses of diffusion tensor imaging and structural magnetic resonance imaging. Psychiatry Res. 156, 93-104. doi: 10.1016/j.pscychresns.2007.02.002

Shattuck, D. W., Mirza, M., Adisetiyo, V., Hojatkashani, C., Salamon, G., Narr, K. L., et al. (2008). Construction of a 3D probabilistic atlas of human cortical structures. Neuroimage 39, 1064-1080. doi: 10.1016/j.neuroimage.2007.09.031

Shergill, S. S., Kanaan, R. A., Chitnis, X. A., O’Daly, O., Jones, D. K., Frangou, S., et al. (2007). A diffusion tensor imaging study of fasciculi in schizophrenia. Am. J. Psychiatry 164, 467-473. doi: 10.1176/appi.ajp.164.3.467

Shi, F., Yap, P. T., Gao, W., Lin, W., Gilmore, J. H., and Shen, D. (2012). Altered structural connectivity in neonates at genetic risk for schizophrenia: a combined study using morphological and white matter networks. Neuroimage 62, 1622-1633. doi: 10.1016/j.neuroimage.2012.05.026

Skelly, L. R., Calhoun, V., Meda, S. A., Kim, J., Mathalon, D. H., and Pearlson, G. D. (2008). Diffusion tensor imaging in schizophrenia: relationship to symptoms. Schizophr. Res. 98, 157-162. doi: 10.1016/j.schres.2007.10.009

Skudlarski, P., Jagannathan, K., Anderson, K., Stevens, M. C., Calhoun, V. D., Skudlarska, B. A., et al. (2010). Brain connectivity is not only lower but different in schizophrenia: a combined anatomical and functional approach. Biol. Psychiatry 68, 61-69. doi: 10.1016/j.biopsych.2010.03.035

Smith, S. M., Jenkinson, M., Johansen-Berg, H., Rueckert, D., Nichols, T. E., Mackay, C. E., et al. (2006). Tract-based spatial statistics: voxelwise analysis of multi-subject diffusion data. Neuroimage 31, 1487-1505. doi: 10.1016/j.neuroimage.2006.02.024

Sporns, O. (2011). The human connectome: a complex network. Ann. N.Y. Acad. Sci. 1224, 109-125. doi: 10.1111/j.1749-6632.2010.05888.x

Steel, R. M., Bastin, M. E., McConnell, S., Marshall, I., Cunningham-Owens, D. G., Lawrie, S. M., et al. (2001). Diffusion tensor imaging (DTI) and proton magnetic resonance spectroscopy (1H MRS) in schizophrenic subjects and normal controls. Psychiatry Res. 106, 161-170. doi: 10.1016/S0925-4927(01)00080-4

Sun, Z., Wang, F., Cui, L., Breeze, J., Du, X., Wang, X., et al. (2003). Abnormal anterior cingulum in patients with schizophrenia: a diffusion tensor imaging study. Neuroreport 14, 1833-1836. doi: 10.1097/01.wnr.0000094529. 75712.48

Sussmann, J. E., Lymer, G. K., McKirdy, J., Moorhead, T. W., Munoz Maniega, S., Job, D., et al. (2009). White matter abnormalities in bipolar disorder and schizophrenia detected using diffusion tensor magnetic resonance imaging. Bipolar Disord. 11, 11-18. doi: 10.1111/j.1399-5618.2008.00646.x

Szeszko, P. R., Ardekani, B. A., Ashtari, M., Kumra, S., Robinson, D. G., Sevy, S., et al. (2005). White matter abnormalities in first-episode schizophrenia or schizoaffective disorder: a diffusion tensor imaging study. Am. J. Psychiatry 162, 602-605. doi: 10.1176/appi.ajp.162.3.602
Szeszko, P. R., Robinson, D. G., Ashtari, M., Vogel, J., Betensky, J., Sevy, S., et al. (2008). Clinical and neuropsychological correlates of white matter abnormalities in recent onset schizophrenia. Neuropsychopharmacology 33, 976-984. doi: 10.1038/sj.npp.1301480

Tuch, D. S., Reese, T. G., Wiegell, M. R., Makris, N., Belliveau, J. W., and Wedeen, V. J. (2002). High angular resolution diffusion imaging reveals intravoxel white matter fiber heterogeneity. Magn. Reson. Med. 48, 577-582. doi: 10.1002/mrm. 10268

Tzourio-Mazoyer, N., Landeau, B., Papathanassiou, D., Crivello, F., Etard, O., Delcroix, N., et al. (2002). Automated anatomical labeling of activations in SPM using a macroscopic anatomical parcellation of the MNI MRI single-subject brain. Neuroimage 15, 273-289. doi: 10.1006/nimg.2001.0978

van den Heuvel, M. P., Mandl, R. C., Stam, C. J., Kahn, R. S., and Hulshoff Pol, H. E. (2010). Aberrant frontal and temporal complex network structure in schizophrenia: a graph theoretical analysis. J. Neurosci. 30, 15915-15926. doi: 10.1523/JNEUROSCI.2874-10.2010

van den Heuvel, M. P., Sporns, O., Collin, G., Scheewe, T., Mandl, R. C., Cahn, W., et al. (2013). Abnormal rich club organization and functional brain dynamics in schizophrenia. JAMA Psychiatry 70, 783-792. doi: 10.1001/jamapsychiatry.2013.1328

Vernon, A. C., Natesan, S., Modo, M., and Kapur, S. (2011). Effect of chronic antipsychotic treatment on brain structure: a serial magnetic resonance imaging study with ex vivo and postmortem confirmation. Biol. Psychiatry 69, 936-944. doi: 10.1016/j.biopsych.2010.11.010

Voineskos, A. N., Foussias, G., Lerch, J., Felsky, D., Remington, G., Rajji, T. K., et al. (2013). Neuroimaging evidence for the deficit subtype of schizophrenia. JAMA Psychiatry 70, 1-9. doi: 10.1001/jamapsychiatry.2013.786

Voineskos, A. N., Lobaugh, N. J., Bouix, S., Rajji, T. K., Miranda, D., Kennedy, J. L., et al. (2010). Diffusion tensor tractography findings in schizophrenia across the adult lifespan. Brain 133, 1494-1504. doi: 10.1093/brain/awq040

Voineskos, A. N., O’Donnell, L. J., Lobaugh, N. J., Markant, D., Ameis, S. H., Niethammer, M., et al. (2009). Quantitative examination of a novel clustering method using magnetic resonance diffusion tensor tractography. Neuroimage 45, 370-376. doi: 10.1016/j.neuroimage.2008.12.028

Voineskos, A. N., Rajji, T. K., Lobaugh, N. J., Miranda, D., Shenton, M. E., Kennedy, J. L., et al. (2012). Age-related decline in white matter tract integrity and cognitive performance: a DTI tractography and structural equation modeling study. Neurobiol. Aging 33, 21-34. doi: 10.1016/j.neurobiolaging.2010.02.009

Walther, S., Federspiel, A., Horn, H., Razavi, N., Wiest, R., Dierks, T., et al. (2011). Alterations of white matter integrity related to motor activity in schizophrenia. Neurobiol. Dis. 42, 276-283. doi: 10.1016/j.nbd.2011.01.017

Wang, F., Sun, Z., Cui, L., Du, X., Wang, X., Zhang, H., et al. (2004) Anterior cingulum abnormalities in male patients with schizophrenia determined through diffusion tensor imaging. Am. J. Psychiatry 161, 573-575. doi: 10.1176/appi.ajp.161.3.573

Wang, Q., Su, T. P., Zhou, Y., Chou, K. H., Chen, I. Y., Jiang, T., et al. (2012). Anatomical insights into disrupted small-world networks in schizophrenia. Neuroimage 59, 1085-1093. doi: 10.1016/j.neuroimage.2011.09.035

Wedeen, V. J., Hagmann, P., Tseng, W. Y., Reese, T. G., and Weisskoff, R. M. (2005). Mapping complex tissue architecture with diffusion spectrum magnetic resonance imaging. Magn. Reson. Med. 54, 1377-1386. doi: 10.1002/mrm.20642

Wedeen, V. J., Wang, R. P., Schmahmann, J. D., Benner, T., Tseng, W. Y., Dai, G., et al. (2008). Diffusion spectrum magnetic resonance imaging (DSI) tractography of crossing fibers. Neuroimage 41, 1267-1277. doi: 10.1016/j.neuroimage.2008.03.036

Wheeler, A. L., Chakravarty, M. M., Lerch, J. P., Pipitone, J., Daskalakis, Z. J., Rajji, T. K., et al. (2014). Disrupted prefrontal interhemispheric structural coupling in schizophrenia related to working memory performance. Schizophr. Bull. 40, 914-924. doi: 10.1093/schbul/sbt100

White, T., Magnotta, V. A., Bockholt, H. J., Williams, S., Wallace, S., Ehrlich, S., et al. (2009). Global white matter abnormalities in schizophrenia: a multisite diffusion tensor imaging study. Schizophr. Bull. 37, 222-232. doi: 10.1093/schbul/sbp088

Wible, C. G., Anderson, J., Shenton, M. E., Kricun, A., Hirayasu, Y., Tanaka, S., et al. (2001). Prefrontal cortex, negative symptoms, and schizophrenia: an MRI study. Psychiatry Res. 108, 65-78. doi: 10.1016/S0925-4927(01)00109-3

Wible, C. G., Shenton, M. E., Hokama, H., Kikinis, R., Jolesz, F. A., Metcalf, D., et al. (1995). Prefrontal cortex and schizophrenia. A quantitative magnetic resonance imaging study. Arch. Gen. Psychiatry 52, 279-288. 
Wolkin, A., Choi, S. J., Szilagyi, S., Sanfilipo, M., Rotrosen, J. P., and Lim, K. O. (2003). Inferior frontal white matter anisotropy and negative symptoms of schizophrenia: a diffusion tensor imaging study. Am. J. Psychiatry 160, 572-574. doi: 10.1176/appi.ajp.160.3.572

Woodruff, P. W., Wright, I. C., Shuriquie, N., Russouw, H., Rushe, T., Howard, R. J., et al. (1997). Structural brain abnormalities in male schizophrenics reflect fronto-temporal dissociation. Psychol. Med. 27, 1257-1266.

Wright, I. C., Sharma, T., Ellison, Z. R., McGuire, P. K., Friston, K. J., Brammer, M. J., et al. (1999). Supra-regional brain systems and the neuropathology of schizophrenia. Cereb. Cortex 9, 366-378.

Yan, H., Tian, L., Yan, J., Sun, W., Liu, Q., Zhang, Y. B., et al. (2012). Functional and anatomical connectivity abnormalities in cognitive division of anterior cingulate cortex in schizophrenia. PLoS ONE 7:e45659. doi: 10.1371/journal.pone.0045659

Yao, L., Lui, S., Liao, Y., Du, M. Y., Hu, N., Thomas, J. A., et al. (2013). White matter deficits in first episode schizophrenia: an activation likelihood estimation meta-analysis. Prog. Neuropsychopharmacol. Biol. Psychiatry 45, 100-106. doi: 10.1016/j.pnpbp.2013.04.019

Zalesky, A., Fornito, A., and Bullmore, E. T. (2010). Network-based statistic: identifying differences in brain networks. Neuroimage 53, 1197-1207. doi: 10.1016/j.neuroimage.2010.06.041

Zalesky, A., Fornito, A., Seal, M. L., Cocchi, L., Westin, C. F., Bullmore, E. T., et al. (2011). Disrupted axonal fiber connectivity in schizophrenia. Biol. Psychiatry 69, 80-89. doi: 10.1016/j.biopsych.2010.08.022

Zhang, H., Schneider, T., Wheeler-Kingshott, C. A., and Alexander, D. C. (2012a). NODDI: practical in vivo neurite orientation dispersion and density imaging of the human brain. Neuroimage 61, 1000-1016. doi: 10.1016/j.neuroimage.2012.03.072
Zhang, R., Wei, Q., Kang, Z., Zalesky, A., Li, M., Xu, Y., et al. (2014). Disrupted brain anatomical connectivity in medication-naive patients with first-episode schizophrenia. Brain Struct. Funct. doi: 10.1007/s00429-0140706-z. [Epub ahead of print].

Zhang, Y., Lin, L., Lin, C. P., Zhou, Y., Chou, K. H., Lo, C. Y., et al. (2012b). Abnormal topological organization of structural brain networks in schizophrenia. Schizophr. Res. 141, 109-118. doi: 10.1016/j.schres.2012.08.021

Zou, L. Q., Xie, J. X., Yuan, H. S., Pei, X. L., Dong, W. T., and Liu, P. C. (2008). Diffusion tensor imaging study of the anterior limb of internal capsules in neuroleptic-naive schizophrenia. Acad. Radiol. 15, 285-289. doi: 10.1016/j.acra.2007.09.026

Conflict of Interest Statement: The authors declare that the research was conducted in the absence of any commercial or financial relationships that could be construed as a potential conflict of interest.

Received: 01 June 2014; paper pending published: 01 July 2014; accepted: 05 August 2014; published online: 25 August 2014.

Citation: Wheeler AL and Voineskos AN (2014) A review of structural neuroimaging in schizophrenia: from connectivity to connectomics. Front. Hum. Neurosci. 8:653. doi: 10.3389/fnhum.2014.00653

This article was submitted to the journal Frontiers in Human Neuroscience.

Copyright (c) 2014 Wheeler and Voineskos. This is an open-access article distributed under the terms of the Creative Commons Attribution License (CC BY). The use, distribution or reproduction in other forums is permitted, provided the original author(s) or licensor are credited and that the original publication in this journal is cited, in accordance with accepted academic practice. No use, distribution or reproduction is permitted which does not comply with these terms. 